\title{
Future changes in the Western North Pacific tropical cyclone activity projected by a multidecadal simulation with a $16-\mathrm{km}$ global atmospheric GCM
}

Article

Published Version

Manganello, J. V., Hodges, K. I., Dirmeyer, B., Kinter, J. L., Cash, B. A., Marx, L., Jung, T., Achuthavarier, D., Adams, J. M., Altshuler, E. L., Huang, B., Jin, E. K., Towers, P. and Wedi, N. (2014) Future changes in the Western North Pacific tropical cyclone activity projected by a multidecadal simulation with a 16-km global atmospheric GCM. Journal of Climate, 27 (20). pp. 7622-7646. ISSN 1520-0442 doi:

https://doi.org/10.1175/JCLI-D-13-00678.1 Available at https://centaur.reading.ac.uk/41489/

It is advisable to refer to the publisher's version if you intend to cite from the work. See Guidance on citing.

Published version at: http://dx.doi.org/10.1175/JCLI-D-13-00678.1

To link to this article DOI: http://dx.doi.org/10.1175/JCLI-D-13-00678.1

Publisher: American Meteorological Society

All outputs in CentAUR are protected by Intellectual Property Rights law, including copyright law. Copyright and IPR is retained by the creators or other copyright holders. Terms and conditions for use of this material are defined in 
the End User Agreement.

www.reading.ac.uk/centaur

\section{CentAUR}

Central Archive at the University of Reading

Reading's research outputs online 


\title{
Future Changes in the Western North Pacific Tropical Cyclone Activity Projected by a Multidecadal Simulation with a 16-km Global Atmospheric GCM
}

\author{
Julia V. Manganello, ${ }^{*}$ KeVin I. Hodges, ${ }^{+}$Brandt Dirmeyer, ${ }^{*}$ JAMES L. Kinter III, ${ }^{\#}$

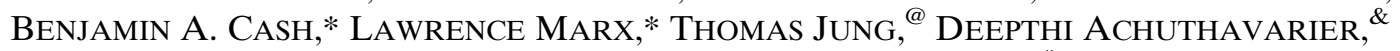 \\ Jennifer M. Adams, ${ }^{*}$ Eric L. Altshuler, ${ }^{*}$ Bohua Huang, ${ }^{*}$ Emilia K. Jin, ${ }^{* *}$ \\ PETER TOWERS, ${ }^{++}$AND NILS WEDI ${ }^{++}$ \\ * Center for Ocean-Land-Atmosphere Studies, Fairfax, Virginia \\ ${ }^{+}$NERC Centre for Earth Observation, University of Reading, Reading, United Kingdom \\ \# Center for Ocean-Land-Atmosphere Studies, and George Mason University, Fairfax, Virginia \\ @ Alfred-Wegener-Institute for Polar and Marine Research, Bremerhaven, Germany \\ ${ }^{\&}$ Center for Ocean-Land-Atmosphere Studies, Fairfax, Virginia, and Universities Space Research Association, \\ Columbia, Maryland \\ ** Korea Institute of Atmospheric Prediction Systems, Seoul, South Korea \\ ${ }^{++}$European Centre for Medium-Range Weather Forecasts, Reading, United Kingdom
}

(Manuscript received 6 November 2013, in final form 17 July 2014)

\begin{abstract}
How tropical cyclone (TC) activity in the northwestern Pacific might change in a future climate is assessed using multidecadal Atmospheric Model Intercomparison Project (AMIP)-style and time-slice simulations with the ECMWF Integrated Forecast System (IFS) at 16-km and 125-km global resolution. Both models reproduce many aspects of the present-day TC climatology and variability well, although the 16-km IFS is far more skillful in simulating the full intensity distribution and genesis locations, including their changes in response to El Niño-Southern Oscillation. Both IFS models project a small change in TC frequency at the end of the twenty-first century related to distinct shifts in genesis locations. In the 16-km IFS, this shift is southward and is likely driven by the southeastward penetration of the monsoon trough/subtropical high circulation system and the southward shift in activity of the synoptic-scale tropical disturbances in response to the strengthening of deep convective activity over the central equatorial Pacific in a future climate. The 16-km IFS also projects about a $50 \%$ increase in the power dissipation index, mainly due to significant increases in the frequency of the more intense storms, which is comparable to the natural variability in the model. Based on composite analysis of large samples of supertyphoons, both the development rate and the peak intensities of these storms increase in a future climate, which is consistent with their tendency to develop more to the south, within an environment that is thermodynamically more favorable for faster development and higher intensities. Coherent changes in the vertical structure of supertyphoon composites show system-scale amplification of the primary and secondary circulations with signs of contraction, a deeper warm core, and an upward shift in the outflow layer and the frequency of the most intense updrafts. Considering the large differences in the projections of TC intensity change between the 16-km and 125-km IFS, this study further emphasizes the need for high-resolution modeling in assessing potential changes in TC activity.
\end{abstract}

\section{Introduction}

Projecting changes in extreme weather events, including tropical cyclones (TCs), remains a critical research

Corresponding author address: Julia V. Manganello, Center for Ocean-Land-Atmosphere Studies, 113 Research Hall, Mail Stop 2B3, George Mason University, 4400 University Drive, Fairfax, VA 22030.

E-mail: julia@cola.iges.org problem of high societal significance. The most intense TCs occur globally in the western North Pacific (NWPac; typhoons), in terms of central pressure and possibly sustained wind speed. The highly populated regions surrounding this basin receive the largest number of TC landfalls in the world. A growing number of numerical modeling studies have sought to project the future changes of typhoon statistics using a variety of future sea surface temperature (SST) distributions and scenarios from the Intergovernmental Panel on Climate Change 
(IPCC) Special Report on Emissions Scenarios (SRES). Their focus has been predominantly on changes in typhoon frequency, genesis locations, and tracks [see review by Knutson et al. (2010)]. While these aspects of TC activity are important, and work still needs to be done to understand and reduce the uncertainties associated with their future projections, a broader question is how the intensities of TCs, and typhoons in particular, are changing (Trenberth 2005). By analyzing the changes in TC intensity and structural life cycle, an effort can be made to better understand the connection, and the associated physical mechanisms, between the projected changes in the intensity distribution and the tropical climate change (Pielke et al. 2005; Knutson et al. 2010). The goal of the present study is to make a contribution in this direction.

An effort to take a closer look at structural changes of future TCs has been mostly limited by insufficient resolution of the atmospheric models used for climate change projections. To properly simulate TC intensity and structure, the model horizontal grid needs to be fine enough, preferably less than $5 \mathrm{~km}$, to resolve sharp gradients in the inner core (e.g., Fierro et al. 2009; Gentry and Lackmann 2010). Therefore, until recently such studies (using models with grid spacing on the order of $10 \mathrm{~km}$ or less) have been mainly restricted to idealized downscaling experiments conducted for specific regions and averaged tropical environments (e.g., Knutson and Tuleya 2004; Hill and Lackmann 2011). Apart from the added benefits of using a global model, simulations of a temporal record of sufficient length are desirable in order to assess the significance of the climate change signal relative to the internal variability (e.g., Bell et al. 2013) and to increase statistical robustness when comparing extremes.

Global atmospheric general circulation models (AGCMs) have progressed to the point where their simulations of the present-day TC climatology, including intensity distribution and structural evolution, are becoming more credible (e.g., Manganello et al. 2012; Murakami et al. 2012b; Strachan et al. 2013). To provide reliable projections of the future changes in TC activity, additional requirements, like the ability to simulate TC variability and the observed trends, need to be met as well. Two recent studies have indicated that these may also benefit from increasing model resolution (Manganello et al. 2012; Strachan et al. 2013). Hence, it is highly desirable that for the purpose of climate change projections, AGCMs should be integrated at the highest resolution feasible.

Our study has capitalized on a successful international collaboration called Project Athena (Jung et al. 2012; Kinter et al. 2013). As part of that project's large suite of experiments, the European Centre for Medium-Range Weather Forecasts (ECMWF) Integrated Forecast System (IFS) weather forecast model was integrated at resolutions of 125 and $16 \mathrm{~km}$ for $47-\mathrm{yr}$ periods covering the present and future climates (section 2). The combination of very high $16-\mathrm{km}$ resolution, which is currently used operationally by ECMWF for medium-range weather forecasts, and the length of the integrations makes this dataset quite unique for studying future changes in TC activity. The focus of this paper is on the NWPac; results for the North Atlantic are presented elsewhere.

The goal of the present study is twofold. First, by evaluating changes in typhoon frequency, genesis locations and tracks, intensity, and lifetime distributions we intend to contribute to current projections of the future change in the typhoon activity using this new dataset (sections 4 and 5). A special emphasis is given to the assessment of the model's skill in reproducing presentday TC climatology and variability (section 3 ) and the significance of the climate change signal relative to the model's natural variability. Second, to validate and better understand the future change in the TC intensity distribution, we perform a comparison of the intensity life cycle and structural properties of a large sample of supertyphoons in the present and future climates (section 6). Finally, the paper is completed by the discussion of the results and conclusions (section 7).

\section{Methodology}

\section{a. Experimental setup}

The ECMWF IFS used in this study is described in detail in Jung et al. (2012) and Manganello et al. (2012). For the climate change simulations within Project Athena, the IFS has been integrated at two horizontal spectral resolutions: T159 and T1279, corresponding approximately to 125 - and $16-\mathrm{km}$ grid spacing, respectively. In the vertical, the IFS has 91 hybrid levels with a top level at $0.01 \mathrm{hPa}$. To represent the current climate, the IFS was integrated continuously for the period of 1960-2007 forced with the observed records of SST and sea ice, similar to the Atmospheric Model Intercomparison Project (AMIP) protocol (Gates 1992). The SST and sea ice boundary conditions are the same $1.125^{\circ}$ data used for the 40-yr European Centre for Medium-Range Weather Forecasts (ECMWF) ReAnalysis (ERA-40; Uppala et al. 2005). These data are monthly before 1990 and weekly starting in 1990, and are interpolated to daily values and in space to the IFS grid at each resolution. Beginning in 2002, daily SST and sea ice are from the operational ECMWF analysis. 
TABLE 1. TC identification criteria.

\begin{tabular}{|c|c|c|}
\hline & \multicolumn{2}{|c|}{ Horizontal resolution of the IFS } \\
\hline & T1279 & T159 \\
\hline 1. Surface $(10-\mathrm{m})$ wind speed threshold $\left(\mathrm{m} \mathrm{s}^{-1}\right.$; intensity threshold) & $15.4^{\mathrm{a}}$ & $11.9^{\mathrm{b}, \mathrm{c}}$ \\
\hline $\begin{array}{l}\text { 2. Difference in vorticity between } 850 \text { and } 250 \mathrm{hPa} \\
\text { (a warm core condition) }\end{array}$ & \multicolumn{2}{|c|}{ Larger than zero for both resolutions } \\
\hline $\begin{array}{l}\text { 3. Vorticity max at each level between } 850 \text { and } 250 \mathrm{hPa} \text { (a coherent } \\
\text { vertical structure condition) }\end{array}$ & \multicolumn{2}{|c|}{ Applied to both resolutions } \\
\hline 4. Criteria $1-3$ are achieved for four consecutive time steps $(24 \mathrm{~h})$ & \multicolumn{2}{|c|}{ Applied to both resolutions } \\
\hline $\begin{array}{l}\text { 5. Cyclogenesis (first identification) occurs between } 0^{\circ}-20^{\circ} \mathrm{N} \\
\text { over land and } 0^{\circ}-30^{\circ} \mathrm{N} \text { over oceans. }\end{array}$ & \multicolumn{2}{|c|}{ Applied to both resolutions } \\
\hline \multicolumn{3}{|c|}{$\begin{array}{l}{ }^{a} \text { Observed tropical storm threshold for 10-min maximum sustained wind (MSW) is used. No correction for model time step is made for } \\
\text { T1279 (10-min time step). }\end{array}$} \\
\hline \multicolumn{3}{|c|}{$\begin{array}{l}\text { b Observed tropical storm threshold for 10-min MSW is used after the correction for model time step. Time step for T159 is } 1 \mathrm{~h} \text {. One-hour } \\
\text { average winds are converted to } 10 \text {-min winds using coefficient } 1.03 \text { (Harper et al. 2009). }\end{array}$} \\
\hline \multicolumn{3}{|c|}{$\begin{array}{l}{ }^{\mathrm{c}} \text { Surface wind speed threshold is further adjusted for model resolution based on Fig. } 2 \text { in Walsh et al. (2007). Values derived from } \\
\text { a selection of Hurricane Research Division (HRD) wind analysis are used. }\end{array}$} \\
\hline
\end{tabular}

The future climate simulations were carried out following the time-slice (TS) approach (Bengtsson et al. 1996). The model was integrated for the period of 20702117 where future SST and sea ice forcing was constructed by adding the difference in the annual cycle of SST and sea ice between 2065-75 and 1965-75, taken from the IPCC Fourth Assessment Report (AR4) integration of the Community Climate System Model, version 3.0 (CCSM3.0), to the 1960-2007 observed record. The 1965-75 (2065-75) data are the average of 8 (6) ensemble members of the twentieth-century (A1B emissions scenario) simulations. In addition to modified boundary conditions, the atmospheric greenhouse gas concentrations were altered to follow the IPCC A1B scenario until the year 2100 and held constant at their 2100 values thereafter. More details on the IFS AMIPstyle and TS experiments are provided in Jung et al. (2012). For the analysis presented in section 5, both IFS T1279 and T159 data are reduced to a common N80 full Gaussian grid resolution.

\section{b. Identification and tracking of tropical cyclones}

The initial TC identification and tracking is similar to that used in Bengtsson et al. (2007a) and is based on the tracking algorithm of Hodges (1994, 1995, 1999). Vortices are detected in the $\mathrm{NH}$ as maxima in the 6-hourly 850 -hPa relative vorticity field with values greater than $5 \times 10^{-6} \mathrm{~s}^{-1}$ (at a spectral resolution of T42). A posttracking lifetime filter of 2 days is applied and a minimum displacement filter of $10^{\circ}(\sim 1000 \mathrm{~km})$ over the lifetime of the vortex. The TC identification criteria (see Table 1) are applied to the raw tracks to separate the simulated TCs from other synoptic systems. As a result, model TCs tend to include both earlier and later stages of a life cycle than the observed storms. To reduce data processing and storage requirements, TC analysis is performed for May-November (MJJASON), which encompasses $90 \%$ of the annual typhoon activity (Chan and Liu 2004). Further details of the TC identification and tracking can be found in Manganello et al. (2012).

\section{c. Observational best-track data}

To compare simulated typhoons with those observed, we use data from the International Best Track Archive for Climate Stewardship (IBTrACS, version v02r01; Knapp et al. 2010). IBTrACS uses 10-min average wind speed at $10 \mathrm{~m}$ elevation for the maximum sustained wind (MSW) estimate, which closely corresponds to the model definition of MSW (see Table 1). We also use the same conversion coefficient between 1- and 10-min winds equal to 0.88 (see Knapp et al. 2010) to adjust TC thresholds. Thus, the "tropical storm" threshold of $17.5 \mathrm{~m} \mathrm{~s}^{-1}(34 \mathrm{kt})$ defined for the 1-min MSW becomes $15.4 \mathrm{~m} \mathrm{~s}^{-1}(30 \mathrm{kt})$ for the $10-\mathrm{min} \mathrm{MSW}$. For the direct comparison with model-simulated tracks, IBTrACS data are processed by applying criteria 1 and 4 of Table 1 .

It must be noted that there are substantial interagency differences in the MSW and minimum sea level pressure (SLP) estimates contributed to the IBTrACS dataset, particularly for the NWPac basin (e.g., Knapp and Kruk 2010). The studies of Knapp and Kruk (2010), Song et al. (2010), and Knapp et al. (2013) have specifically highlighted the dependence of the uncertainty in intensity, as well as some integral measures of the TC activity, on the observed TC intensity with large discrepancies for category 4-5 supertyphoons (Song et al. 2010). Since the mean values of intensity provided by IBTrACS are used in our study, these factors need to be kept in mind. However, we do not believe that the main results of section 3 would change substantially as a consequence of this uncertainty. 
TABLE 2. Climatological mean and standard deviation (in parenthesis) of the TC frequency, power dissipation index, mean peak intensity, and mean lifetime of TCs for the MJJASON season of 1975-2007 for IBTrACS (OBS) and IFS AMIP simulations. In addition to the total TC frequency, data are separately shown for tropical storms (TS) and storms of categories 1-2 (CAT 1-2) and categories 3-5 (CAT 3-5). Units for TC frequency are numbers per season. Differences between the model results and the corresponding observational values that are statistically significant at the $95 \%$ confidence level, using a two-sided Student's $t$ test, are shown in boldface. Degrees of freedom are computed taking into account serial correlation in the time series.

\begin{tabular}{|c|c|c|c|c|c|c|c|c|c|}
\hline & \multicolumn{3}{|c|}{ OBS } & \multicolumn{3}{|c|}{ IFS T1279 } & \multicolumn{3}{|c|}{ IFS T159 } \\
\hline & TS & CAT $1-2$ & CAT 3-5 & TS & CAT $1-2$ & CAT $3-5$ & TS & CAT 1-2 & CAT $3-5$ \\
\hline Total TC frequency & & $22.6(3.6)$ & & & $33.5(5.3)$ & & & $26.2(5.5)$ & \\
\hline $\begin{array}{l}\text { TC frequency per storm category } \\
\text { based on surface wind speed* }\end{array}$ & $8.3(2.4)$ & $7.2(2.7)$ & $7.2(2.6)$ & $20.5(4.2)$ & $8.1(2.2)$ & $4.9(2.0)$ & $20.6(5.1)$ & $5.6(2.1)$ & $\mathbf{0 . 0 3}(0.17)$ \\
\hline $\begin{array}{l}\text { TC frequency per storm category } \\
\text { based on central pressure** }\end{array}$ & $6.9(2.1)$ & $4.8(2.1)$ & $10.7(3.4)$ & $18.3(3.7)$ & $5.0(2.1)$ & $10.1(2.9)$ & $22.4(5.2)$ & $1.9(1.3)$ & $1.9(1.3)$ \\
\hline $\begin{array}{l}\text { Power dissipation index } \\
\qquad\left(10^{11} \mathrm{~m}^{3} \mathrm{~s}^{-2}\right)\end{array}$ & & $4.2(1.4)$ & & & $3.5(1.2)$ & & & $\mathbf{0 . 7 2}(0.19)$ & \\
\hline Mean peak intensity $\left(\mathrm{m} \mathrm{s}^{-1}\right)$ & & $36.3(3.1)$ & & & $29.2(1.8)$ & & & $19.2(1.0)$ & \\
\hline Mean lifetime (days) & & $10.2(1.4)$ & & & $\mathbf{1 2 . 5}(1.4)$ & & & $11.7(1.7)$ & \\
\hline
\end{tabular}

* Classification is based on Saffir-Simpson scale using maximum sustained surface wind speed (e.g., Landsea 1993). Wind speed thresholds are adjusted for the 10-min average wind using 0.88 scaling (see Knapp et al. 2010) and further adjusted for model resolution for IFS T159 version only as in Manganello et al. (2012).

** Classification is based on Saffir-Simpson scale using central pressure (e.g., Landsea 1993).

\section{Tropical cyclone activity in the present-day (AMIP-style) simulation}

To assess the credibility of the simulated future changes in TC activity, we start with a brief evaluation of the model's skill in reproducing present-day TC climatology and variability.

\section{a. Tropical cyclone climatology}

Seasonal mean TC frequency is significantly higher than observed for both models (see Table 2), which is consistent with the results of Manganello et al. (2012). This distinct IFS bias is likely a consequence of a set of environmental conditions associated with overly strong precipitation over the NWPac warm pool area. Enhanced precipitation and related convergence errors are associated with positive relative vorticity errors to the northwest $\left(\sim 10^{\circ}-25^{\circ} \mathrm{N}\right)$ and an increase in the vertical wind shear (VWS) to the south (not shown). A deeper monsoon trough and enhanced positive vorticity favor higher convective activity. The relative humidity is also elevated in the region, as amplified convective activity increases the supply of water vapor in the atmosphere.

If, on the other hand, the total seasonal TC counts are considered by storm category (see Table 2), it becomes clear that the positive bias in the simulated TC frequency in both models is entirely due to the overprediction of the weakest systems (tropical storms). The T1279 TC frequency is similar to the observed for storms of categories $1-2$, although lower for categories 3-5. The T159 model significantly underpredicts storms of all categories irrespective of the classification system used (see below).
Although operational classification by central pressure was ended in the 1990s, it is worthwhile to compare model results with observations using this approach. As opposed to minimum central pressure, models do a much poorer job in simulating maximum surface wind as a result of, for example, insufficient model resolution or deficient parameterizations of surface momentum flux (e.g., Powell et al. 2003). It is interesting that using this classification the T1279 mean TC frequency is quite close to that observed for both TC category groups (see Table 2).

The seasonal mean power dissipation index (PDI), which is an integral measure of the TC activity, ${ }^{1}$ is well within the limits of the observational estimate for the T1279 model and considerably lower for the T159 (see Table 2). Both models underestimate mean peak intensity and somewhat overestimate mean lifetime of the storms. The latter is largely due to the tracking procedure (see Manganello et al. 2012; Strachan et al. 2013).

Intensity distributions (Figs. 1a,b) show a fairly good correspondence between the frequency of occurrence of the simulated and observed TCs at the high end of the intensity scale for the T1279 model only. At the low end, the storms are overpredicted, particularly for the T159 model, which is consistent with the results in Table 2. The overall correspondence for minimum SLP is much better than for maximum surface wind speed, although some simulated storms attain lower SLP than observed.

\footnotetext{
${ }^{1} \mathrm{PDI}$ is defined as the cube of the peak surface wind at any given time in a storm integrated over its lifetime (Emanuel 2005).
} 

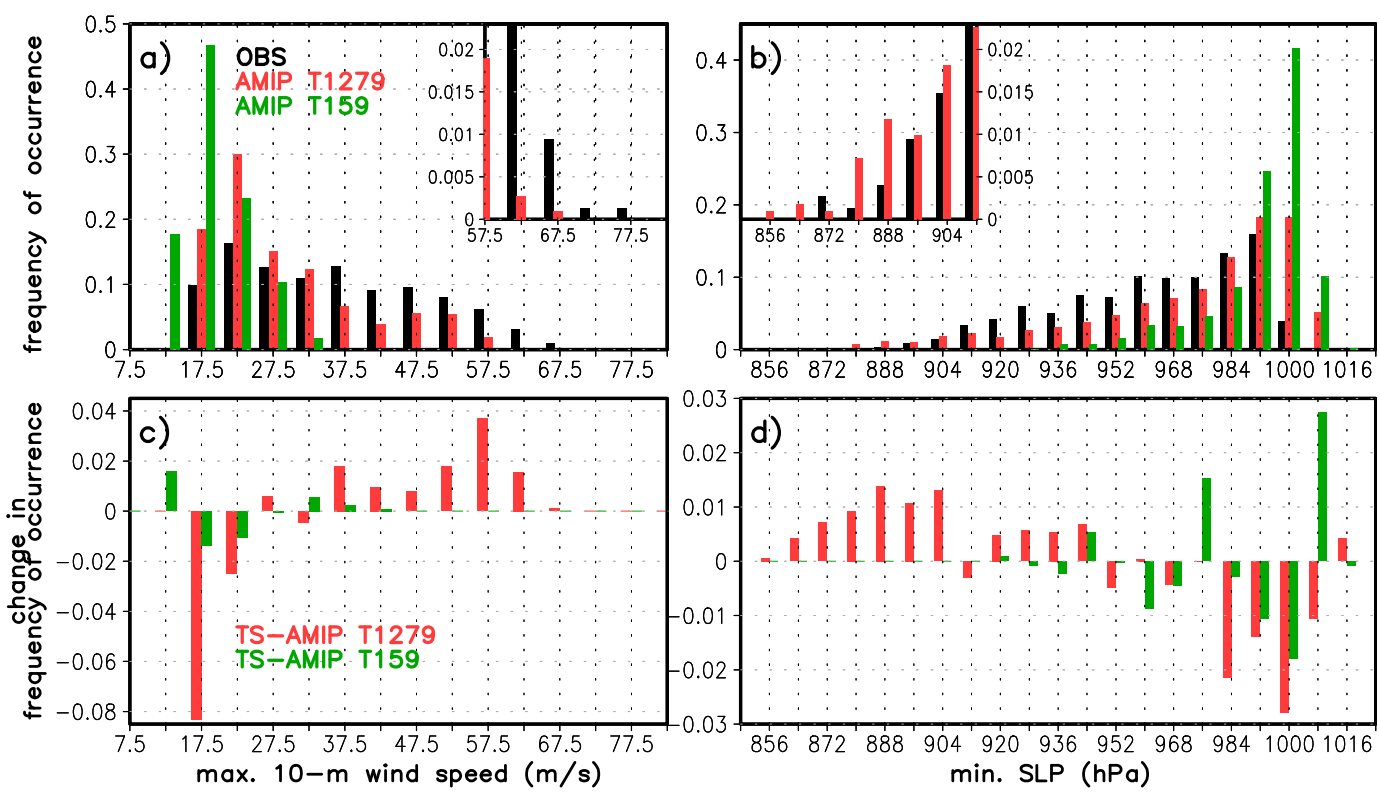

FIG. 1. (top) Frequency distributions of (a) the maximum attained 10-m wind speed and (b) the minimum SLP from the IBTrACS data (OBS; black bars), AMIP T1279 (red bars), and AMIP T159 (green bars) for MJJASON of 19752007. Inset plots show the tail of the distributions. (bottom) Future change in the frequency distributions of (c) the maximum attained 10-m wind speed and (d) the minimum SLP for TS and AMIP at T1279 (red bars) and T159 (green bars) based on $47 \mathrm{yr}$ of data.

This has also been found in Manganello et al. (2012), which contains some discussion of this result.

The genesis density in the T1279 model has a distribution similar to that observed, except for a slight northwest shift of the highest concentration region of cyclogenesis likely related to the precipitation bias described above (not shown). This deficiency is mostly due to the weakest storms, as the genesis density computed only for typhoons, which are equivalent to hurricanes of category 1 or higher, is realistic with the centers located to the south/southeast of the overall distribution (Figs. 2a,b). The track density for these stronger storms in the T1279 model is also quite comparable to the observed (Figs. 2d,e). The corresponding distributions for the T159 model are much less coherent and could be deemed unrealistic (Figs. 2c,f). The genesis potential index analysis, which is able to separate the effect of the large-scale fields on the cyclogenesis from the in situ resolution effect, produces similar results for both versions of the model (not shown). This suggests that large deficiencies in the simulation of genesis density in the T159 model are primarily a result of low resolution. These results are in agreement with Walsh et al. (2013), who also found that the pattern of cyclone formation improves with the model resolution increase.

In summary, the T1279 model shows a good correspondence with observations in terms of the various TC activity metrics presented above, especially for the "hurricane" strength TCs that will be at the center of further analysis. In contrast, while the overall performance of the T159 model is perhaps satisfactory considering its coarse resolution, it is quite poor in terms of these stronger storms.

\section{b. Tropical cyclone variability}

\section{1) SEAsonal CyCle AND INTERANNUAL VARIABILITY}

The seasonal cycle of the TC frequency is fairly realistic in the T1279 model with errors largely confined to the beginning and the end of the season (not shown). The T159 model has much larger errors, where monthly TC frequency increases monotonically throughout the season instead of displaying a peak in August-September.

Correlations of the observed and simulated seasonal mean TC frequencies are quite low for both models but show much higher values for the PDI, which could in principle capture more of the climate influence (see Table 3). Although there is a general consensus that the observed trend in the NWPac TC frequency over the last 35 years is insignificant (e.g., Wu et al. 2008; Knutson et al. 2010), estimates of the trend in the PDI or other similar integral quantities range from a $35 \%$ increase (Emanuel 2007) to an insignificant decrease (Chan and Liu 2004; Klotzbach 2006; Kossin et al. 2007; Wu et al. 2008). The simulated trends in the TC frequency and PDI are small 

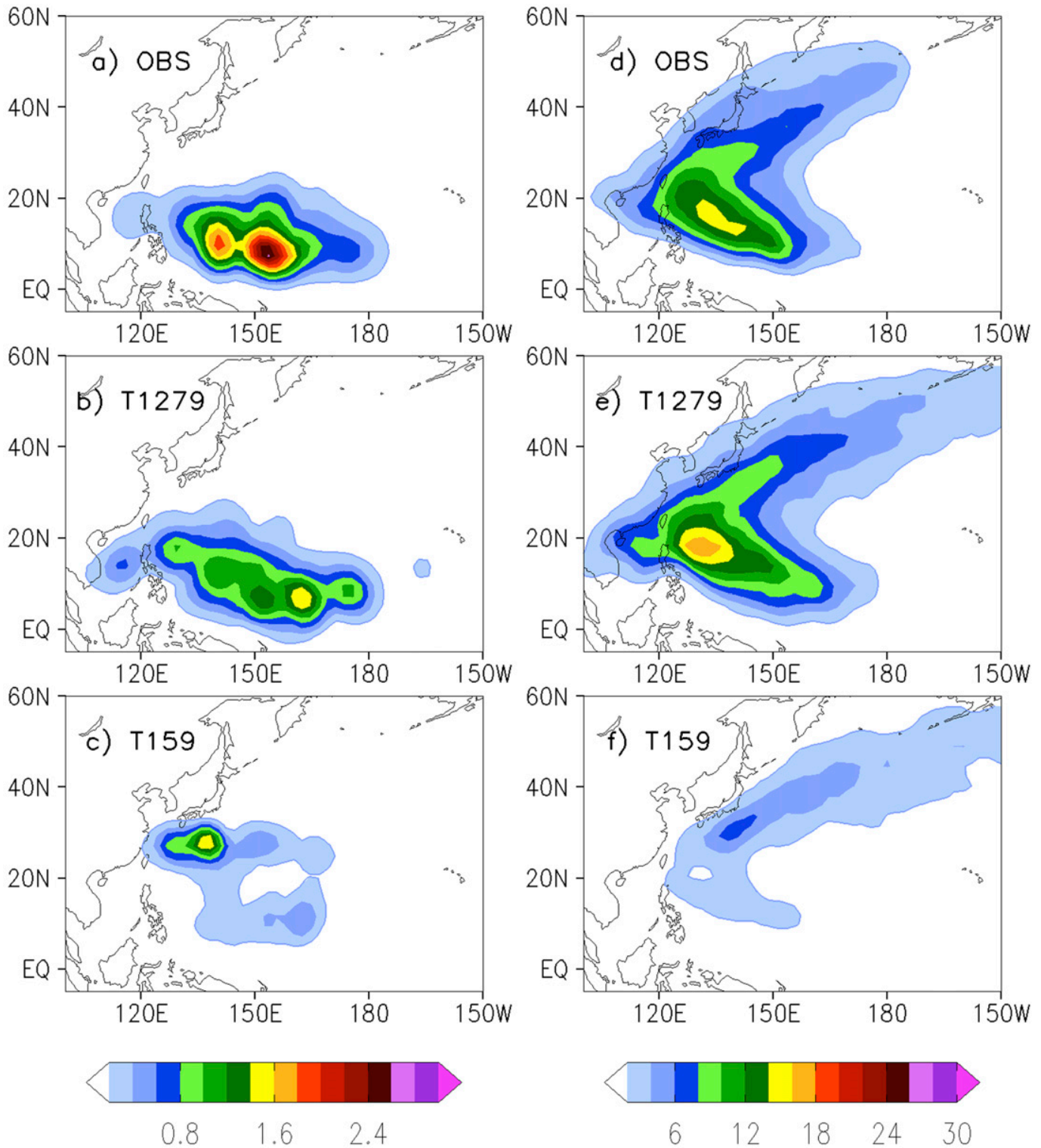

FIG. 2. (left) Genesis and (right) track densities of tropical cyclones equivalent to hurricanes of categories 1-5 as number density per season per unit area equivalent to a $5^{\circ}$ spherical cap for (a),(d) IBTrACS (OBS), (b),(e) AMIP T1279, and (c),(f) AMIP T159 based on MJJASON of 1975-2007.

and insignificant for both versions of the model (not shown). Having only one realization, it is difficult to make any definite conclusions regarding the skill of the model in reproducing interannual variability and longterm changes. For instance, during 1990-2007 the correlations of the detrended TC frequency and PDI increase sharply to $0.6(0.6)$ and $0.63(0.55)$ respectively for the T1279 (T159) model.

Although El Niño-Southern Oscillation (ENSO) has a major influence on the TC activity in the NWPac [see section $3 b(2)$ ], year-to-year variations in the location and strength of the monsoon trough are also known to impact the intensity and lifetime of typhoons (e.g., Chia and Ropelewski 2002). To reduce sampling errors, we show this influence as a change in the normalized cumulative frequency of occurrence of the maximum attained $10-\mathrm{m}$ wind speed and TC lifetime for relatively active and inactive years during 1975-2007. ${ }^{2}$ The

\footnotetext{
${ }^{2}$ These years are computed based on the observed (IBTrACS) detrended PDI time series and include 1976, 1982, 1987, 1990, 1991, 1992, 1994, 1997, and 2004 for active years and 1975, 1977, 1978, 1988, 1993, 1995, 1998, 1999, and 2007 for inactive years.
} 
TABLE 3. Correlation coefficients between the seasonal mean simulated and observed (IBTrACS) TC frequency and PDI for MJJASON of 1975-2007. One-tailed $p$ values are given in parenthesis. Boldface (italic) values indicate that the correlation coefficient is statistically significant at the $95 \%$ (90\%) confidence level using a one-sided Student's $t$ test and taking into account serial correlation in the time series.

\begin{tabular}{lcc}
\hline \hline & IFS T1279 & IFS T159 \\
\hline TC frequency & $0.32(0.0384)$ & $0.17(0.1787)$ \\
Power dissipation index & $\mathbf{0 . 4 8}(0.0030)$ & $\mathbf{0 . 4 0}(0.0098)$ \\
\hline
\end{tabular}

observed distributions show a shift toward higher intensity and lifetime values during the active years (Figs. 3a,b). Both IFS models reproduce this tendency but strongly underestimate the magnitude of the change. The bulk of the intensity response in the T159 model is also confined to very low intensities, which is clearly due to its low resolution (see Fig. 1a). For the T1279 model, the shape of this distribution becomes much more realistic. The overall weakness of the simulated response could be attributed in part to sampling issues (a small number of years in each category and only one realization of the present-day climate), although insufficient resolution could be a limiting factor as well. It appears that this deficiency is quite common among the current high-resolution models (e.g., Zhao and Held 2010) and even occurs in some TC forecasting models (Bender et al. 2010). In the case of lifetime distributions, the differences in the tracking procedures could also be important. Additionally, the total (forced and unforced) TC intensity and lifetime variability in the model is found to be quite low as well: the respective change in the cumulative frequency distributions of these quantities is only about half of the observed (Figs. 3a,b; see dashed lines with open circles).

\section{2) ReLATIONSHIP WiTH ENSO}

ENSO has a dominant effect on the TC activity in the NWPac because of its large influence on the strength and position of the monsoon trough, as well as VWS and thermodynamic conditions in the region (e.g., Wang and Chan 2002; Chan and Liu 2004; Camargo et al. 2007). During the positive ENSO phase, the monsoon trough tends to be stronger and extends farther to the southeast. Additionally, in the southeastern part of the region, VWS decreases, and the mean ascending motion and moisture content of the midtroposphere increase. Opposite changes take place in the northwestern part of the domain. These climatological variations in concert lead to southeast-to-northwest shifts in the TC genesis during ENSO events (Chia and Ropelewski 2002; Wang and Chan 2002) that do not necessarily result in large changes in the TC counts, and is reflected in the low correlation between the observed TC frequency and the Niño-3.4 index (see Table 4). On the other hand, ENSO has a much stronger influence on the TC intensity and lifetime: during El Niño events, TCs tend to be more intense, with longer lifetimes and more recurving trajectories (Wang and Chan 2002; Camargo and Sobel 2005), which leads to a high correlation between the PDI and the Niño-3.4 index (Table 4). Both versions of the IFS reproduce these connections fairly well, showing low correlations for the TC frequency and much higher correlations for the PDI (Table 4). The tendency of the observed TCs to be more intense and long-lived during El Niño versus La Niña events is also evident in Figs. 3c and 3d. [ENSO events are computed based on the MayNovember average monthly Niño-3.4 index obtained from the National Center for Atmospheric Research (NCAR) Climate and Global Dynamics Division (CGD) Climate Analysis Section (http://www.cgd.ucar.edu/cas/ catalog/climind/Nino_3_3.4_indices.html). $]^{3}$ As in the previous section, both versions of the IFS reproduce this tendency but strongly underestimate the magnitude of the change. (In the T159 model, the intensity response could be considered marginal. PDI variations seem to be primarily driven by the lifetime changes in this model.)

Geographical changes in the TC genesis locations during ENSO events are shown in more detail in Fig. 4. Consistent with the changes in the environmental conditions described above, genesis density tends to increase (decrease) to the east (west) of $150^{\circ} \mathrm{E}$ longitude (Fig. 4a). The T1279 model reproduces this shift quite well, although the center of the decreased genesis density is somewhat to the southeast of the observed (Fig. 4b). The T159 model, however, does not simulate the clear dipole pattern: large positive changes occur both around the date line and west of $150^{\circ} \mathrm{E}$, whereas negative changes are weak and occur in multiple locations (Fig. 4c).

\section{Projected changes in the tropical cyclone activity at the end of the twenty-first century: Comparison of the time-slice and AMIP-style simulations}

\section{a. Tropical cyclone frequency, intensity, and power dissipation index}

Both IFS models project a small and insignificant change in the NWPac TC frequency toward the end of the twenty-first century (see Table 5). However, the

\footnotetext{
${ }^{3}$ Years include 1977, 1982, 1987, 1991, 1993, 1994, 1997, 2002, 2004, and 2006 for El Niño years and 1975, 1978, 1984, 1985, 1988, 1989, 1998, 1999, 2000, and 2007 for La Niña years.
} 
Change in Cumulative Distribution
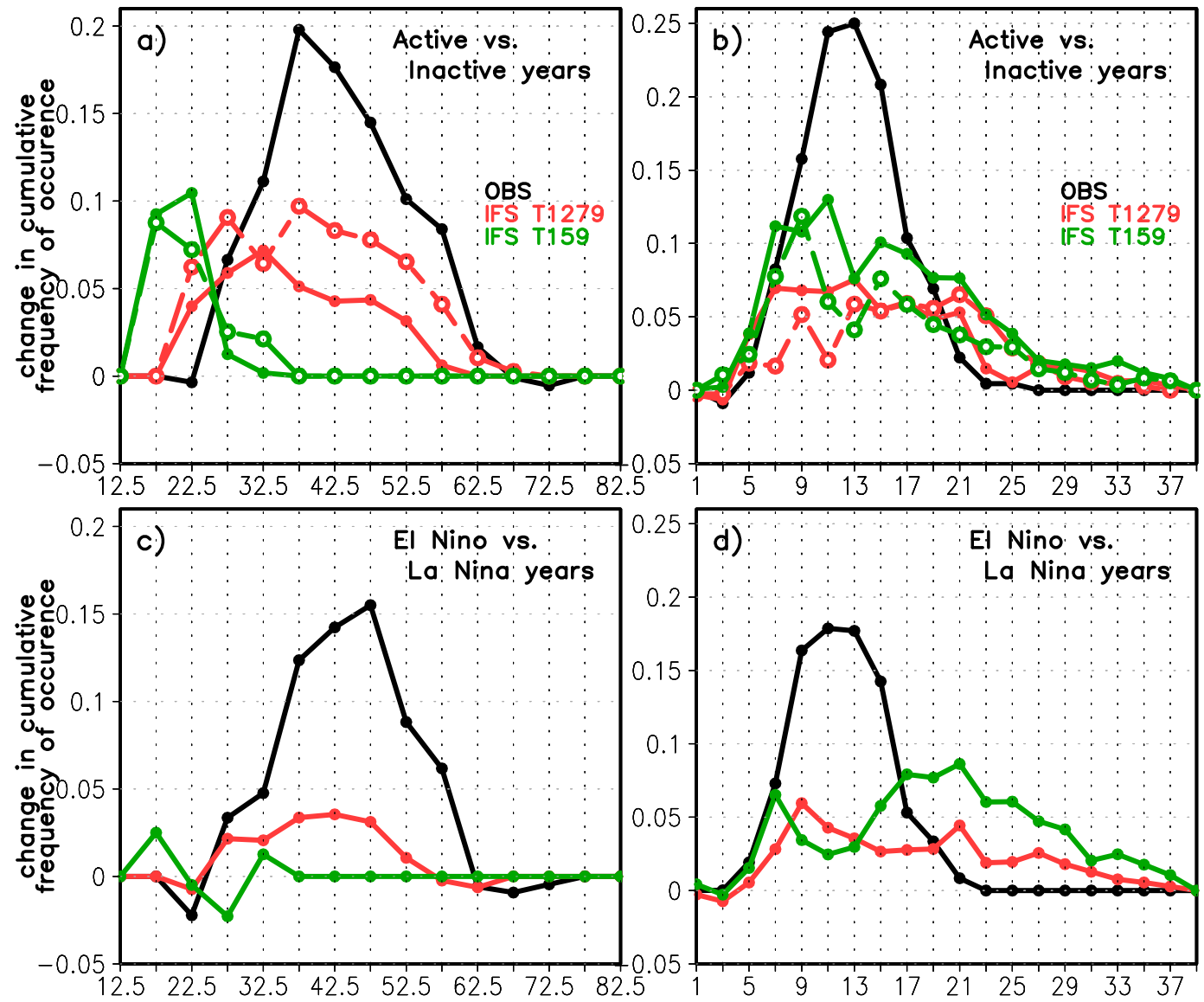

d)

El Nino vs.
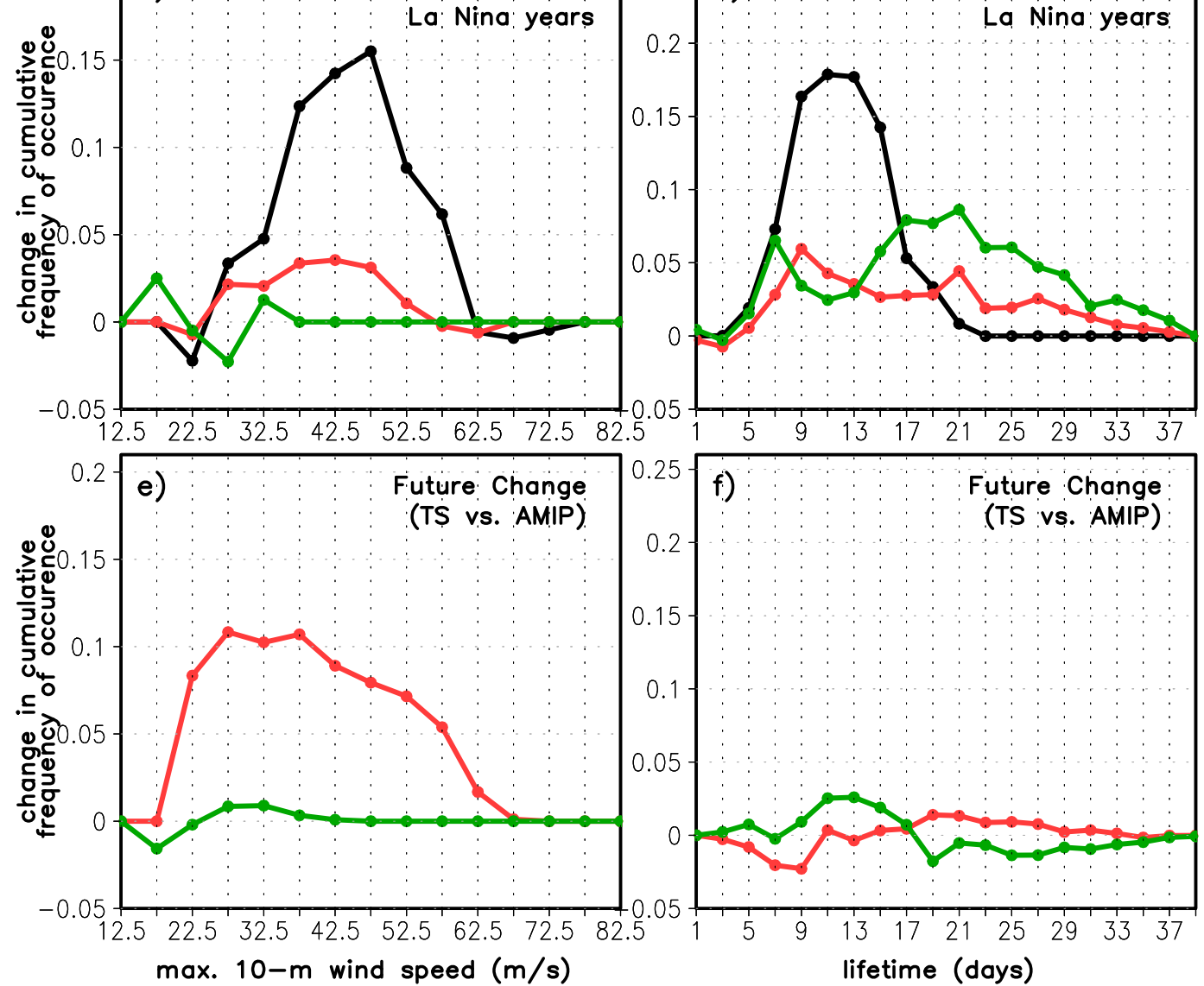

FIG. 3. Change in the cumulative frequency distributions of (left) the maximum attained $10-\mathrm{m}$ wind speed and (right) the TC lifetime for (a),(b) active vs inactive years and (c),(d) El Niño vs La Niña years based on MJJASON of 1975-2007 for the IBTrACS data (OBS; black line), AMIP T1279 (solid red line, closed circles) and AMIP T159 (solid green line, closed circles). Dashed lines with open circles in (a) and (b) show corresponding changes based on the individual model's definition of active/inactive years. (e),(f) As in (a),(b), but for future vs present climate (TS vs AMIP) based on $47 \mathrm{yr}$ of data. 
TABLE 4. Correlation coefficients between the seasonal mean TC frequency and PDI and the Niño-3.4 index for MJJASON of 19752007. One-tailed $p$ values are given in parenthesis. Boldface (italic) values indicate that the correlation coefficient is statistically significant at the $95 \%$ (90\%) confidence level using a one-sided Student's $t$ test and taking into account serial correlation in the time series.

\begin{tabular}{lccc}
\hline \hline & OBS & IFS T1279 & IFS T159 \\
\hline TC frequency & $0.13(0.2381)$ & $0.32(0.0340)$ & $0.34(0.0253)$ \\
Power dissipation & $\mathbf{0 . 6 8}(0.0001)$ & $\mathbf{0 . 4 2}(0.0086)$ & $\mathbf{0 . 3 9}(0.0134)$ \\
$\quad$ index & & & \\
\hline
\end{tabular}

T1279 IFS also shows a significant reduction in the frequency of the tropical storms and a significant increase in the typhoon counts, particularly for categories 3-5 ( $\sim 70 \%$ increase; Table 5$)$. These results are also reflected in the changes of the TC intensity distributions (Figs. 1c,d), which are found to be statistically significant using a $\chi^{2}$ test only for the T1279 model. In contrast, the T159 model produces a weaker and statistically insignificant response in the TC intensity, which is likely a consequence of its coarse resolution (e.g., Bengtsson et al. 2007b; Murakami and Sugi 2010). The tendency toward stronger storms in a warmer climate in the T1279 IFS is in general agreement with a number of other highresolution studies [see the review in Knutson et al. (2010)], and a roughly $10 \%$ increase in the fraction of typhoons in this model (Fig. 3e) is consistent with the findings of, for example, Zhao et al. (2009). Moreover, in this study we also find that future changes in the TC intensities projected by the T1279 model are comparable with the range of intensity variations due to the model's natural variability (forced plus unforced; Figs. 3a,e). To understand the underlying causes of such a large intensity response in the T1279 model is the focus of later in the paper.

Consistent with the change in the intensity distributions, mean peak TC intensity in the T1279 IFS increases by $12 \%$

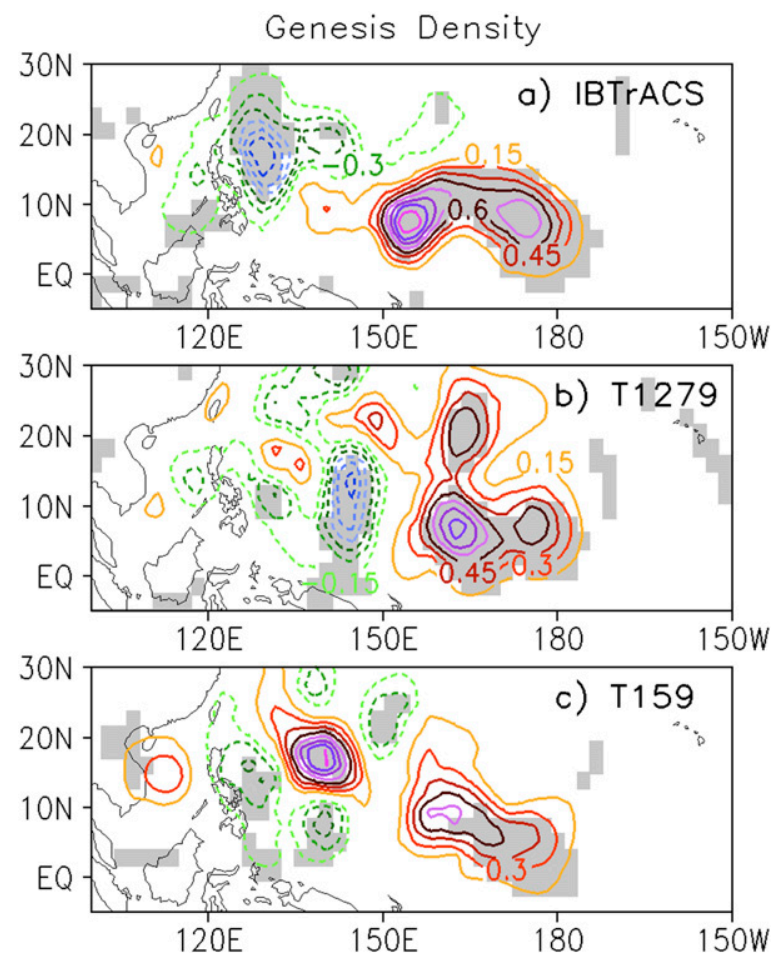

FIG. 4. Differences in the composites of the TC genesis density between El Niño and La Niña years scaled by 0.5 , for (a) IBTrACS, (b) AMIP T1279, and (c) AMIP T159 for MJJASON of 1975-2007. Contour interval is 0.15 . Positive (negative) contours are solid (dashed) with the starting value of $0.15(-0.15)$. Shading represents differences significant at the $95 \%$ confidence level using a permutation Monte Carlo approach (for details, see Bengtsson et al. 2006; Hodges 2008).

in a warmer climate contributing to a $51 \%$ increase in the PDI (Table 5), in response to about 2.2-K SST warming over the tropical NWPac (see section 5a). Notably, the mean increases in the PDI and mean peak intensity

TABLE 5. Future change (TS minus AMIP) and future fractional change (in parentheses) in the seasonal mean TC frequency, power dissipation index, mean peak intensity, and mean lifetime of TCs based on the MJJASON season of the 47-yr IFS AMIP and TS simulations. In addition to the total TC frequency, data are separately shown for tropical storms (TS) and storms of categories 1-2 (CAT 1-2) and categories 3-5 (CAT 3-5). Differences between the model results that are statistically significant at the 95\% confidence level, using a twosided Student's $t$ test, are shown in boldface. Degrees of freedom are computed taking into account serial correlation in the time series.

\begin{tabular}{|c|c|c|c|c|c|c|}
\hline & \multicolumn{3}{|c|}{ IFS T1279 } & \multicolumn{3}{|c|}{ IFS T159 } \\
\hline & TS & CAT 1-2 & CAT 3-5 & TS & CAT 1-2 & CAT 3-5 \\
\hline Total TC frequency, counts per season & & $+2.2(+7 \%)$ & & & $-1.1(-4 \%)$ & \\
\hline $\begin{array}{l}\text { TC frequency per storm category } \\
\text { based on surface wind speed* }\end{array}$ & $-2.4(-12 \%)$ & $+\mathbf{1 . 3}(+17 \%)$ & $+\mathbf{3 . 3}(+70 \%)$ & $-0.8(-4 \%)$ & $-0.4(-9 \%)$ & $+\mathbf{0 . 2}(+450 \%)$ \\
\hline $\begin{array}{l}\text { Power dissipation index } \\
\qquad\left(10^{11} \mathrm{~m}^{3} \mathrm{~s}^{-2}\right)\end{array}$ & & $+\mathbf{1 . 8}(+51 \%)$ & & & 0 & \\
\hline Mean peak intensity $\left(\mathrm{m} \mathrm{s}^{-1}\right)$ & & $+\mathbf{3 . 4}(+12 \%)$ & & & $-0.03(-0.2 \%)$ & \\
\hline Mean lifetime (days) & & $+0.02(+0.1 \%)$ & & & $+0.06(+0.5 \%)$ & \\
\hline
\end{tabular}

* Classification is based on Saffir-Simpson scale using maximum sustained surface wind speed (e.g., Landsea 1993). Wind speed thresholds are adjusted for the 10-min average wind using 0.88 scaling (see Knapp et al. 2010) and further adjusted for model resolution for IFS T159 version only as in Manganello et al. (2012). 

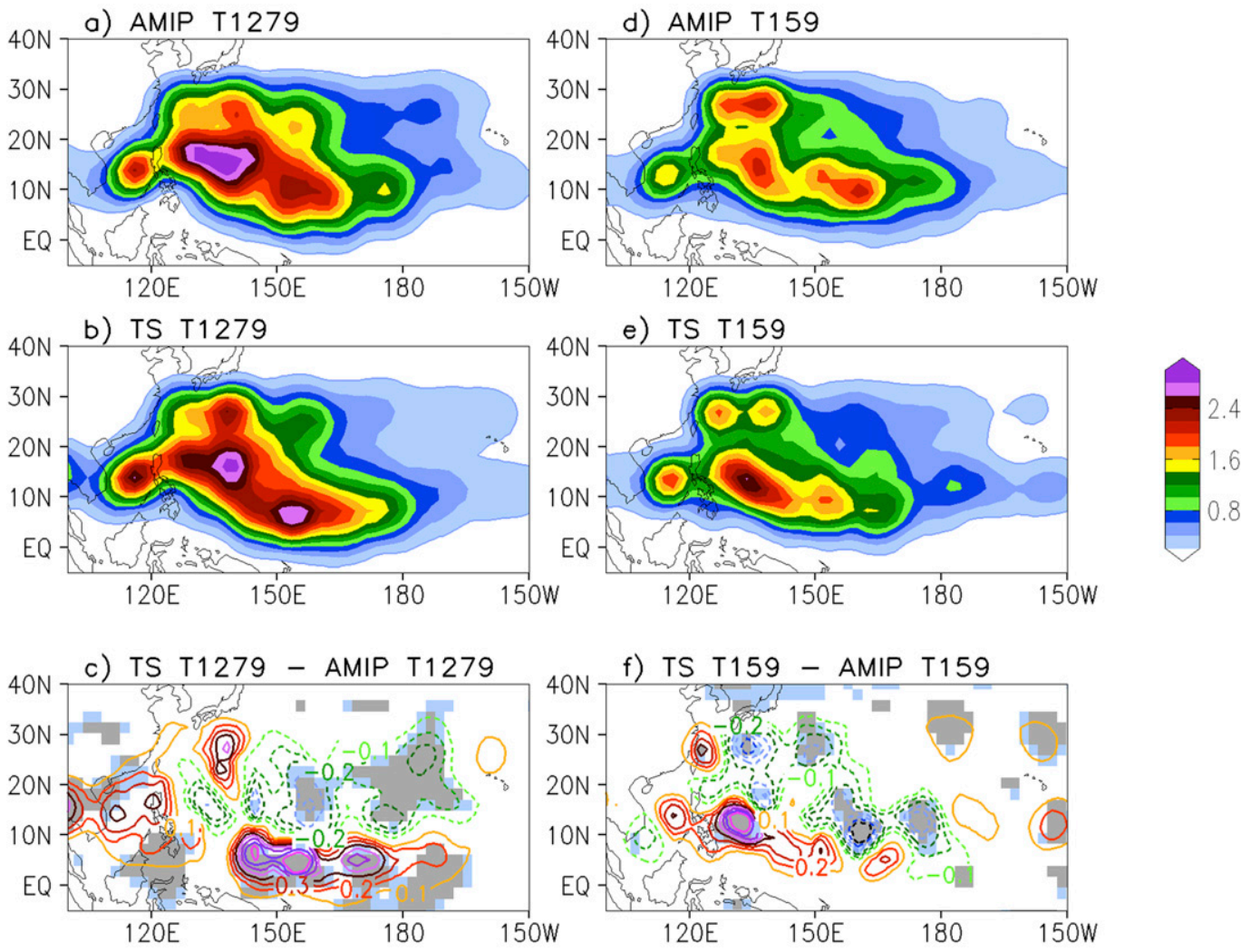

FIG. 5. Genesis densities as number density per season per unit area equivalent to a $5^{\circ}$ spherical cap for (a) AMIP T1279 based on MJJASON of 1961-2007, (b) TS T1279 based on MJJASON of 2071-2117, and (c) the difference between TS T1279 and AMIP T1279. (d)-(f) As in (a)-(c), but for T159 resolution. Contour interval is 0.1. Positive (negative) contours are solid (dashed) with the starting value of $0.1(-0.1)$. Gray (light blue) shading shows differences significant at the $95 \%(90 \%)$ confidence level using a permutation Monte Carlo approach (for details, see Bengtsson et al. 2006, Hodges 2008).

substantially exceed their standard deviations, which are $1.2 \times 10^{11} \mathrm{~m}^{3} \mathrm{~s}^{-2}$ and $2.1 \mathrm{~m} \mathrm{~s}^{-1}$, respectively, in the AMIP and roughly the same in the TS simulation. In contrast, mean TC lifetime and lifetime distribution remain virtually the same for both models (Table 5, Fig. 3f). Compared to its high-resolution version, the TC activity response to climate change in the T159 IFS is quite benign. The T1279 results here are quite similar to the findings of Stowasser et al. (2007) based on a $0.5^{\circ}$ regional model simulation. They also report a $50 \%$ increase in the PDI, which is dominated by an increase in the frequency of the most intense storms, as a change in the lifetime and increase in the total TC frequency are insignificant. However, in their study, the warming scenario is quite severe, resulting in about 3-K surface warming in the tropical NWPac. Similar results are also reported by Yamada et al. (2010), who used a 14-km global cloud-system-resolving model.

\section{b. Genesis locations and tracks}

In response to future climate change, a clear southward (southwestward) shift of the main genesis regions takes place in the T1279 (T159) IFS, with a smaller and less significant increase in the genesis density over the South China Sea (Fig. 5), which overall is consistent with a small change in the basinwide seasonal mean TC frequency in both models. In turn, both models project track density increases along the southwestern corridor from as far as the date line for T1279 to Southeast Asia and decreases in the center of the basin (Fig. 6). Based on the T1279 IFS, track density also increases along the northwestern corridor from Japan to high latitudes.

The above patterns of change in tracks are consistent with the results of Wu and Wang (2004), who examined the sensitivity of track changes to the shifts in the TC formation locations. There is also some similarity with the work of Bengtsson et al. (2006) where they report an equatorward translation of tracks in the eastern part of the domain and into the central Pacific. However, a number of recent studies suggest rather a substantial eastward migration of storms leading to a reduction in genesis frequency over most of the NWPac and an increase in the central Pacific or farther east of the date 

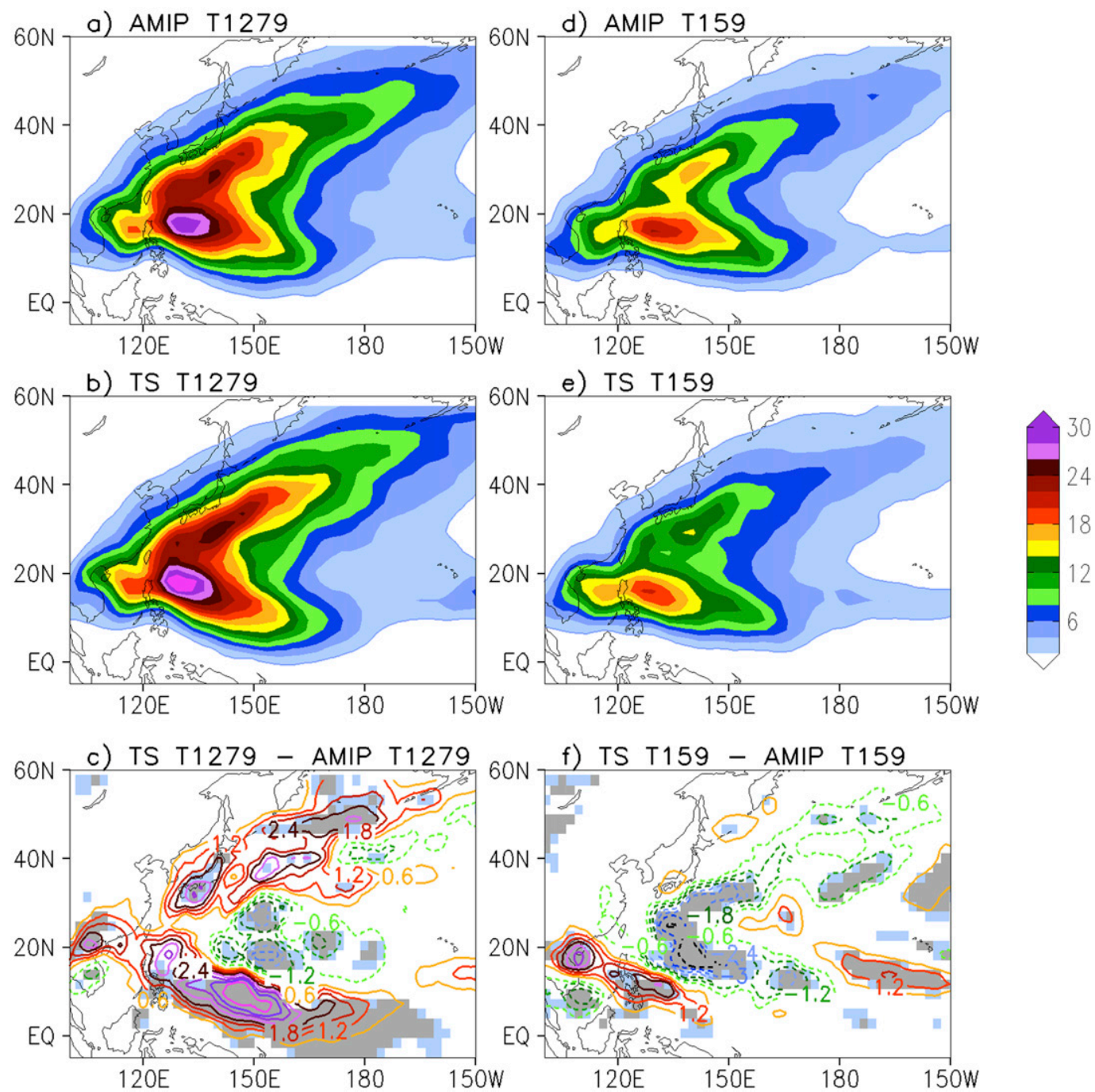

FIG. 6. As in Fig. 5, but for track density. Contour interval is 0.6. Positive (negative) contours are solid (dashed) with starting values of $0.6(-0.6)$. Gray (light blue) shading shows differences significant at the $95 \%(90 \%)$ confidence level using a permutation Monte Carlo approach (for details, see Bengtsson et al. 2006; Hodges 2008).

line, possibly with some poleward shift ( $\mathrm{Li}$ et al. 2010; Murakami et al. 2011; Murakami et al. 2012a,b; Zhao and Held 2012). We will attempt to further address these differences in section 7 .

\section{Impact of future changes in the large-scale atmospheric conditions}

We find that future changes in the large-scale atmospheric conditions that are known to have a direct effect on tropical cyclogenesis and TC development in the NWPac largely stem from the response of the hydrological cycle in the tropics to the prescribed pattern of SST warming. We therefore start this analysis by examining changes in the tropical precipitation and circulation in response to climate change.

\section{a. SST forcing and the change in the tropical precipitation}

The prescribed future changes in the seasonal mean SST in our TS experiments (Fig. 7a) have broad similarities with the multimodel projection performed for the IPCC AR4 using the same A1B emissions scenario (e.g., Vecchi and Soden 2007a). Although the maximum warming is also in the equatorial Pacific, it extends farther to the west with the largest SST anomalies occurring west of the date line. In addition, relatively high SST values are found over the Maritime Continent and the eastern part of the north Indian Ocean. In this respect, SST forcing in our study bears less resemblance to an El Niño-like forcing used in a number of recent works (e.g., Murakami et al. 2011, 2012b). The net effect of these 


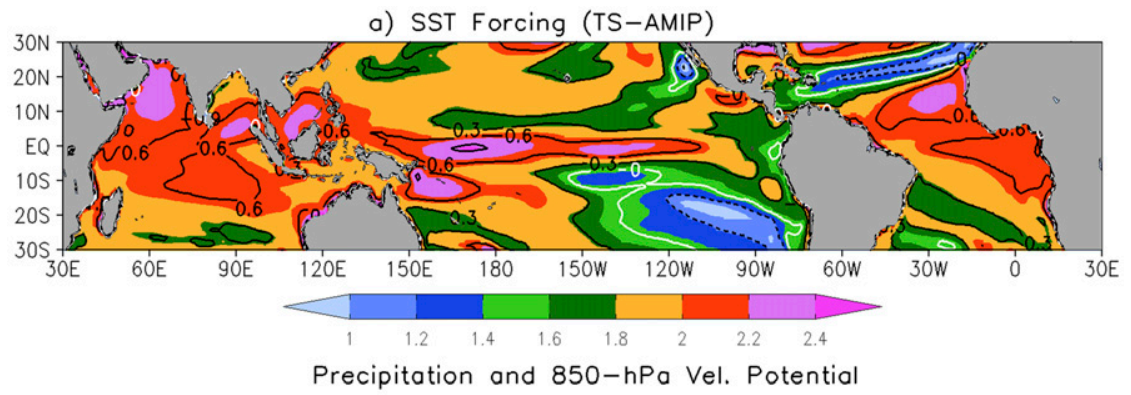

b) TS T1279 - AMIP T1279

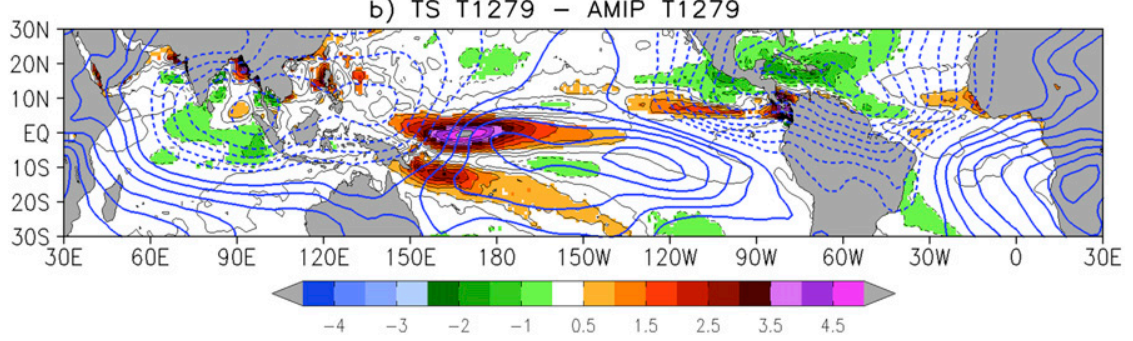

FIG. 7. (a) Prescribed SST forcing (K) as a difference between the MJJASON mean SST from the TS and AMIP experiments. Contours show the difference between the local and the tropical mean $\left(20^{\circ} \mathrm{S}-20^{\circ} \mathrm{N}\right) \mathrm{SST}$ change. Contour interval is $0.3 \mathrm{~K}$, positive (negative) contours are solid (dashed), zero contour is white. (b) MJJASON mean projected future change in the total precipitation rate $\left(\mathrm{mm}\right.$ day $^{-1}$; shading and thin black contours) and the 850 -hPa velocity potential $\left(10^{6} \mathrm{~m}^{2} \mathrm{~s}^{-1}\right.$; thick blue contours) for T1279 IFS based on the $47 \mathrm{yr}$ of data. Contour interval is $0.5 \mathrm{~mm}$ day $^{-1}$ and $0.1 \times 10^{6} \mathrm{~m}^{2} \mathrm{~s}^{-1}$, positive (negative) contours are solid (dashed) with a starting value $0.5(-0.5) \mathrm{mm} \mathrm{day}^{-1}$ and $0.1(-0.1) \times 10^{6} \mathrm{~m}^{2} \mathrm{~s}^{-1}$. Shading shows precipitation changes that are statistically significant at the $95 \%$ confidence level using a two-sided Student's $t$ test.

spatial inhomogeneities (i.e., neglecting regionally uniform warming) is an eastward penetration of the NWPac warm pool, its enhancement at the equator between about $150^{\circ} \mathrm{E}$ and the date line, and a weakened equatorial cold tongue in the future relative to the present climatology (not shown).

The IFS at T1279 simulates a future increase in rainfall largely confined to the central equatorial Pacific (Fig. 7b) similar to the results of Vecchi and Soden (2007b), who examined the IPCC AR4 multimodel ensemble mean response. The magnitude and location of this increase is in fact comparable to the ones during an El Niño event, which is found to be quite realistic (not shown). In turn, the low-level circulation exhibits an enhanced convergence over the central equatorial $\mathrm{Pa}$ cific and anomalous divergence over the broad region to the west (Fig. 7b), extending to the north Indian Ocean, suggesting respective changes in the convective mass flux. Using 500-hPa pressure velocity $(\omega)$ as a proxy for convective mass flux ${ }^{4}$ [see Vecchi and Soden (2007b) for more details], we find that deep convective activity is

\footnotetext{
${ }^{4}$ Principal results are insensitive to the choice of other midtropospheric levels (e.g., 400 or $700 \mathrm{hPa}$ ).
}

likely reduced over most of the tropical NWPac except for the equatorial region between about $150^{\circ} \mathrm{E}$ and the date line where there is a large and statistically significant increase in the midtropospheric vertical ascent (see Fig. 8b). This appears to have a large influence, both direct and indirect, on the southward shift of the TC genesis locations in the high-resolution version of the IFS (see section 5b). In contrast, precipitation response in the lower-resolution version of the IFS is quite different in the western part of the domain where it closely follows the pattern of local SST change (not shown), which partly determines the southwest preference in the shift of genesis locations and tracks in this model.

\section{b. Regional-scale changes in the environmental fields}

Here we extend our analysis of the climate change induced shifts in genesis to include other large-scale fields that are known for their ability to influence spatial and temporal variability of TC formation.

For the IFS at T1279, the southward shift in the main genesis regions shows a connection to the patterns of change in the $850-\mathrm{hPa}$ relative vorticity, $500-\mathrm{hPa} \omega$, and 700-hPa relative humidity (Figs. 5c and 8, Table 6). Specifically, an increase in genesis to the south is consistent with the enhanced low-level vorticity due to the 
TS - AMIP (T1279)

a) 850-hPa Relative Vorticity

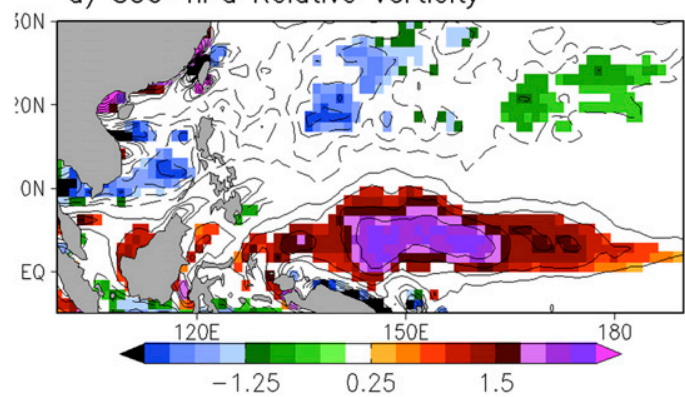

c) $700-\mathrm{hPa}$ Relative Humidity

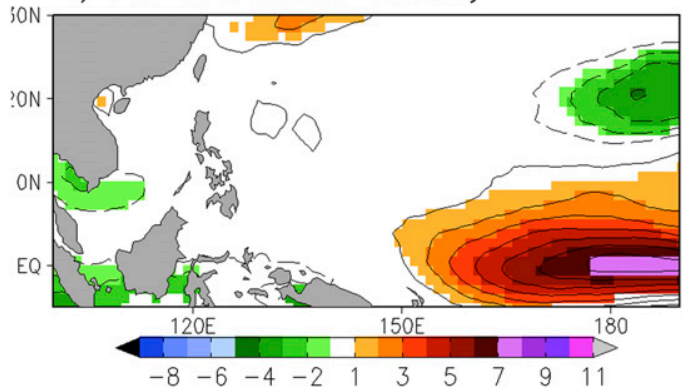

e) VWS of Zonal Wind

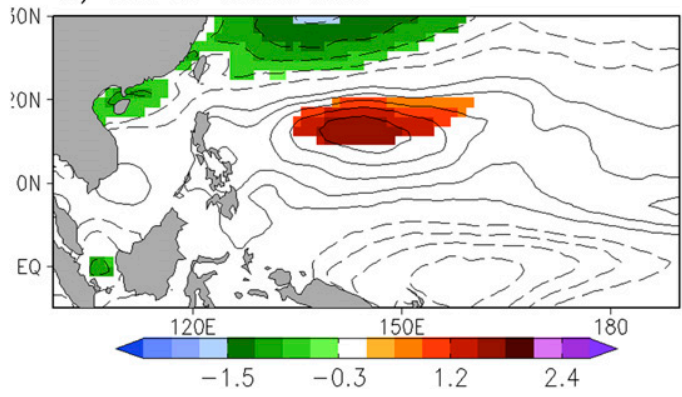

b) Negative of $500-\mathrm{hPa}$ Omega

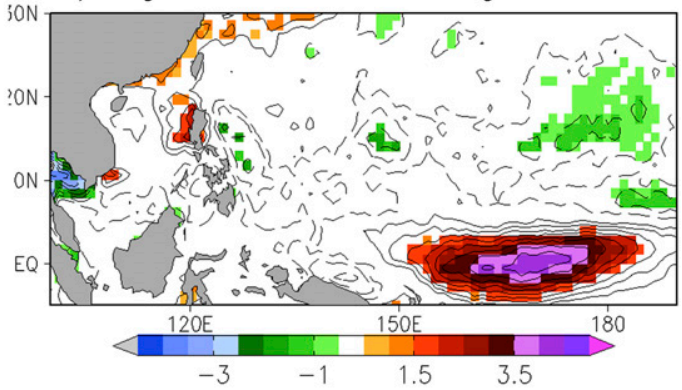

d) Potential Intensity

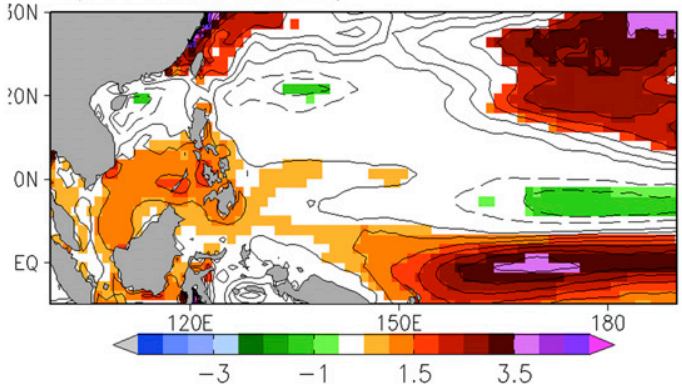

f) Track Density of Trop. Disturbances

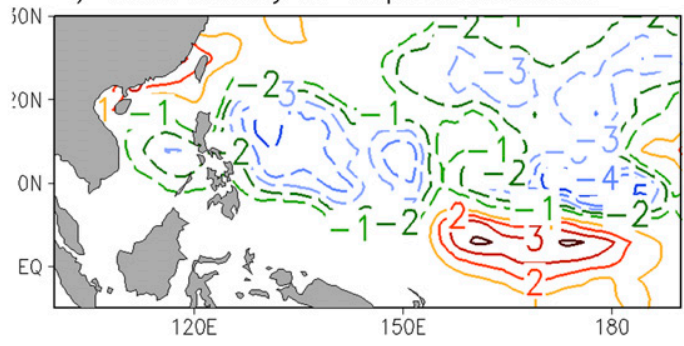

FIG. 8. MJJASON mean projected future change (TS - AMIP) in (a) 850-hPa relative vorticity $\left(10^{-6} \mathrm{~s}^{-1}\right)$, (b) negative of $500-\mathrm{hPa} \omega\left(10^{-2} \mathrm{~Pa} \mathrm{~s}^{-1}\right)$, (c) $700-\mathrm{hPa}$ relative humidity (\%), (d) potential intensity $\left(\mathrm{m} \mathrm{s}^{-1}\right)$, (e) vertical shear of zonal wind ( $\mathrm{m} \mathrm{s}^{-1}$; no absolute value taken), and (f) track density of synoptic-scale tropical disturbances (number density per season per unit area equivalent to a $5^{\circ}$ spherical cap) for IFS at T1279 based on the 47-yr simulations. In (a)-(e) shading shows changes significant at the $95 \%$ confidence level using a two-sided Student's $t$ test. In (f) contour interval is 1.0. Positive (negative) contours are solid (dashed) with the starting value of $1.0(-1.0)$.

southeastward extension of the monsoon trough (Fig. 8a), stronger deep convective activity (Fig. 8b), and midtropospheric moistening (Fig. 8c) associated with the increased precipitation in the central equatorial Pacific (Fig. 7b). In turn, the depressed TC genesis to the north is likely linked to the anomalous anticyclonic vorticity, weaker convection, and reduced relative humidity in the east. Although VWS changes are not correlated with the overall shift in the genesis density (see Table 6), in general agreement with the results of Zhao and Held (2012), the broad region of weakened VWS of total wind south of about $15^{\circ} \mathrm{N}$ (not shown) is consistent with the enhanced genesis. Potential intensity
(PI) changes show little connection with the genesis changes (Fig. 8d, Table 6), as also reported in Murakami et al. (2011, 2012b) and Zhao and Held (2012). PI changes closely resemble the regional SST anomalies, and the largest increase in PI takes place too far south to have a direct impact on the TC genesis, both in agreement with Vecchi and Soden (2007a).

Geographical shifts in the TC genesis in a future climate have also been linked to a change in the activity of synoptic-scale tropical disturbances due to the background vertical shear of zonal wind and low-level divergence changes (e.g., Li et al. 2010). In our study, we find a marginal strengthening of the easterly wind shear 
TABLE 6. Pattern correlation coefficients between the future change in the TC genesis density and the projected change in the selected atmospheric fields for the IFS T1279 based on the MJJASON season of the 47-yr AMIP and TS simulations. (Values for VWS and PI are not shown since they explain less than $10 \%$ of the variance in the TC genesis density change.) Correlation coefficients are computed over the domain of $5^{\circ} \mathrm{S}-30^{\circ} \mathrm{N}, 100^{\circ} \mathrm{E}-$ $170^{\circ} \mathrm{W}$ and listed in the descending order.

\begin{tabular}{lc}
\hline & IFS T1279 \\
\hline 850-hPa relative vorticity & 0.44 \\
Track density changes of the synoptic-scale & 0.43 \\
$\quad$ propagating tropical disturbances & \\
Total precipitation & 0.42 \\
Negative $\omega$ at $500 \mathrm{hPa}$ & 0.34 \\
Negative of the vertical shear of zonal wind & 0.32 \\
$\quad$ (no absolute value taken) & \\
700-hPa relative humidity & 0.31 \\
\hline
\end{tabular}

* Data are based on 28 and 30 nonconsecutive seasons out of 47 for the AMIP and TS simulations respectively.

over the region and a weakening to the north (Fig. 8e). This pattern of change along with the enhanced lowlevel convergence and divergence over the corresponding areas (Fig. 7b) are quite consistent with the southward displacement in the synoptic-scale activity (Fig. 8f). ${ }^{5} \mathrm{We}$ also find that changes in these atmospheric conditions as well as the number of preexisting disturbances are correlated with the TC genesis density response in the region (see Table 6).

Based on these results, it follows that the climate change induced southward shift in the tropical cyclogenesis in the IFS at T1279 likely occurs in response to 1) the strengthening of the monsoon trough environment in the southeastern part of the domain and the southward penetration of the NWPac subtropical high, 2) the southward shift in the activity of the synoptic-scale tropical disturbances, and 3) the amplification of deep convective activity over the central equatorial Pacific. In contrast, changes in the TC formation locations in the T159 model are more sensitive to the large-scale shifts in the VWS pattern (not shown) and do not appear to have any relationship with the indicators of the change in the activity of the synoptic-scale tropical disturbances (see Table 7).

\section{Composite analysis of the tropical cyclone intensification and structural changes}

Here, we return to the question of TC intensity changes in a future climate. Our focus will be the comparison of

\footnotetext{
${ }^{5} \mathrm{We}$ define this measure here as a track density of all identified low-level tropical disturbances that last at least 2 days and travel farther than $1000 \mathrm{~km}$ with the exception of the TCs (see also section $2 b$ ).
}

TABLE 7. As in Table 6, but for IFS T159. Values for total precipitation, VWS, 700-hPa relative humidity, PI, track density changes of the synoptic-scale propagating tropical disturbances and vertical shear of zonal wind are not shown since they explain less than $10 \%$ of the variance in the TC genesis density change.

\begin{tabular}{lc}
\hline \hline 850-hPa relative vorticity & IFS T159 \\
\hline
\end{tabular}

the most intense TCs in the AMIP and TS simulations aimed at identifying changes in the statistical properties of this category of storms and physical processes that govern their evolution. To do this we use a compositing technique to create a sample of the most intense typhoons in both simulations. Owing to the long integration time of the AMIP and TS experiments, we are able to isolate approximately 50 (100) supertyphoons of category 4 (category 3 ) or higher in the T1279 model. The storms are sampled following the methodology described in Bengtsson et al. (2007b) at the time when they achieve their maximum intensity, as indicated by the lifetime maximum 10-m wind speed [see Manganello et al. (2012) for more detail]. The characteristics of these TCs are given in Table 8. The following analysis is primarily based on the 50-storm composites; results from the 100 storms are reported where appropriate. We emphasize that the size of these supertyphoon composites is unique for global climate change modeling studies at such high $(16 \mathrm{~km})$ resolution.

The most intense supertyphoons in the AMIP T1279 simulation originate south of $20^{\circ} \mathrm{N}$ and between $120^{\circ} \mathrm{E}$ and the date line (Fig. 9a), similar to the observed sample (not shown). In a future climate, their genesis shifts southward and eastward (Fig. 9b) in agreement with an overall pattern of change (Fig. 5c). As a result, track density increases in the southwestern corridor and the northwestern one east of Japan, and decreases in the center of the basin and over the South China Sea (not shown). These changes are more pronounced when the 100 -storm composites are compared. Despite the geographical shift in their formation, future supertyphoons attain their maximum intensity in about the same region east of the Philippines (Figs. 9a,b).

\section{a. Intensity life cycle}

An upward shift in the frequency of the most intense TCs under climate change could be brought about by several factors that are not necessarily mutually exclusive: 1) an increase in the duration of storms, as longerlived storms have more time to intensify; 2) a higher intensification rate; and 3) an increase in the PI or decrease in the VWS along the tracks, which can directly lead to higher lifetime peak intensities (Emanuel 2000; 
TABLE 8. Characteristics of the composited TCs for IBTrACS (OBS) and IFS at T1279 AMIP (TS) simulation for the MJJASON season of 1961-2007 (2071-2117).

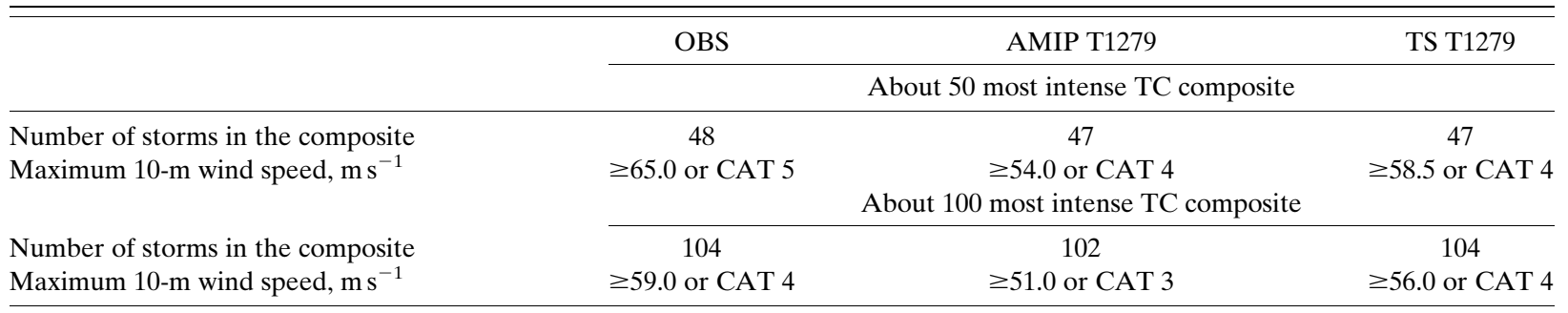

Zeng et al. 2007, and references therein). In addition to other factors described below, PI and VWS could also alter the storm intensification rate (e.g., Nolan et al. 2007; Zeng et al. 2007). [Storm translation is also found to affect TC intensities and intensification (Zeng et al. 2007) but one aspect of this influence by means of ocean interaction is not captured in our study, and therefore storm translation is not examined here.]

Despite the southward shift of storms in a future climate (T1279 model), their overall lifetime distribution does not change much (Fig. 3f). Moreover, the average time it takes a supertyphoon to reach peak intensity is actually shorter in a future climate, which implies a faster growth rate: 11.7 (12.0) days in the TS simulation compared to 13.8 (13.7) days in the AMIP based on the 50-storm (100 storm) composites, where the differences are statistically significant at the $95 \%$ confidence level in both cases. It follows that changes in the storm duration do not explain the higher frequency of supertyphoons in a future climate.

To evaluate the intensification rate, we compare the temporal evolution of the composited storms by constructing intensity life cycles, both in terms of the maximum 10-m wind speed and minimum SLP (Fig. 10). To do so, each storm is centered on the time when it achieves maximum intensity in terms of the 10-m wind speed. Simulated storms both in the present and future climates do not grow as fast as the observed ones, consistent with Manganello et al. (2012). The growth also starts earlier in the life cycle, and the gestation period when a storm grows only weakly is longer (not shown). This could be partly a consequence of the tracking procedure, as storms in the model are identified much earlier in their life cycle. Nevertheless, Fig. 10 clearly shows that the intensification rate of supertyphoons increases in a future climate.

In addition to higher rate of development, future storms also display higher maximum intensities. At the peak (zero offset in Fig. 10), maximum 10-m wind speed is on average higher by $4.7 \mathrm{~m} \mathrm{~s}^{-1}$ ( $8 \%$ increase) and minimum SLP is lower by $4.2 \mathrm{hPa}(5 \%$ increase in pressure deficit relative to the ambient environment) in TS versus AMIP. If 100-storm composites are considered, the change in wind speed and SLP are respectively
$+4.7 \mathrm{~m} \mathrm{~s}^{-1}(9 \%$ increase $)$ and $-9.6 \mathrm{hPa}(11 \%$ increase in pressure deficit; not shown). The latter estimate is comparable to the results of Hill and Lackmann (2011), who report an increase in the TC intensity for the same A1B emission scenario equal to an 8 -hPa reduction in
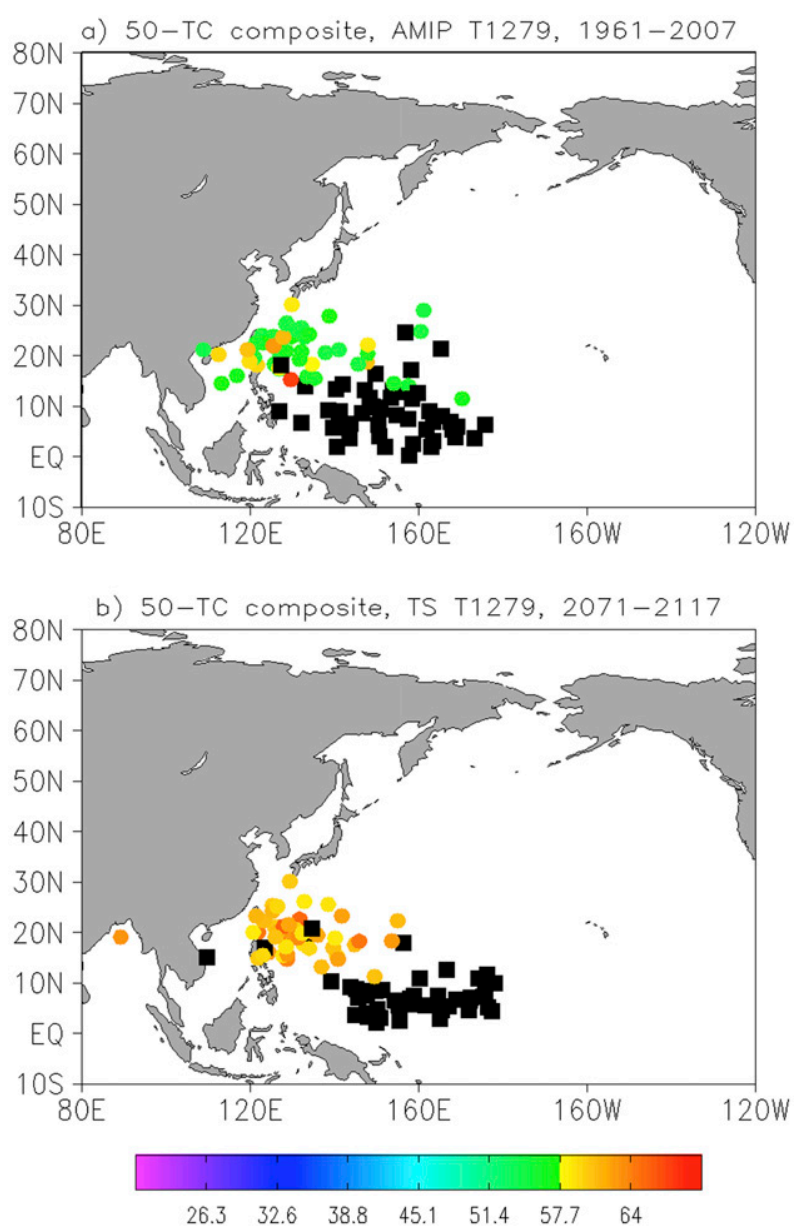

FIG. 9. Locations of genesis (black squares) and the lifetime maximum 10-m wind speed (colored circles) of the TCs in the composites of about 50 most intense supertyphoons (see Table 8) from (a) AMIP T1279 for the MJJASON season of 1961-2007 and (b) TS T1279 for the MJJASON season of 2071-2117. Colors correspond to the magnitude of the lifetime maximum $10-\mathrm{m}$ wind speed $\left(\mathrm{m} \mathrm{s}^{-1}\right)$, as shown on the scale. 

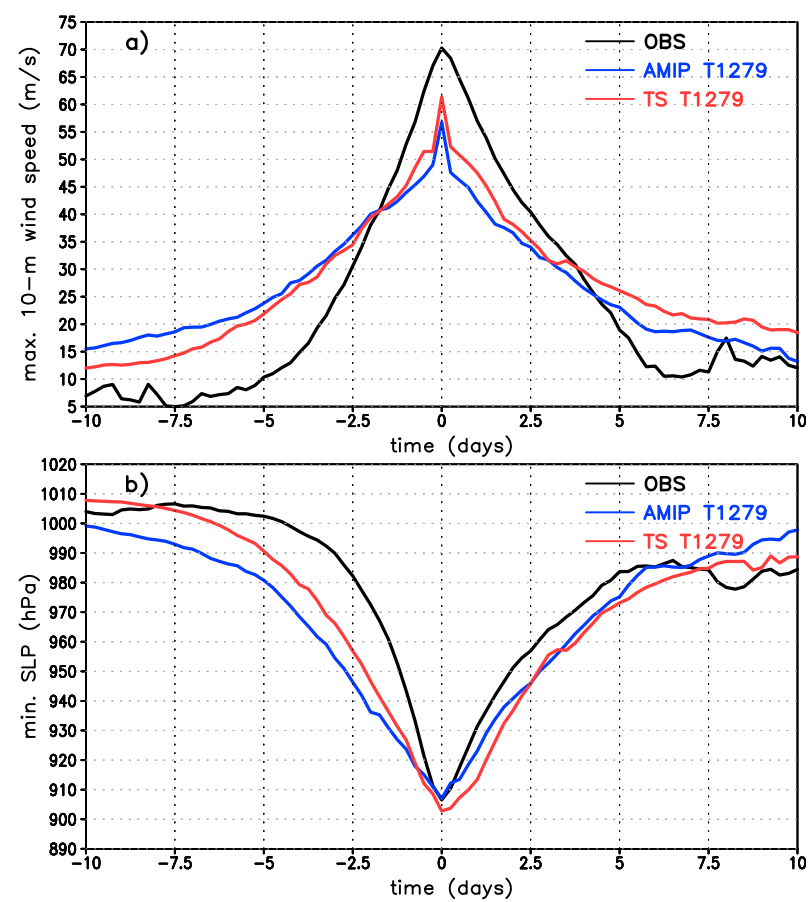

FIG. 10. Life cycle composites of (a) the maximum 10-m wind speed and (b) the minimum SLP, based on the composites of about 50 most intense supertyphoons (see Table 8) for IBTrACS (OBS; black), AMIP T1279 (blue), and TS T1279 (red). Negative (positive) offsets indicate pre (post) intensification.

minimum SLP, or a $10 \%$ increase in pressure deficit. However, their results are based on an idealized downscaling study using a 6-km grid model with explicit convection, focused on the North Atlantic and utilizing outputs from multiple global GCMs. It also ignores the impact of future changes in VWS-a scenario quite compatible with our results that show a small change in VWS over the region in a future climate (see section $5 b$ ).

Although the seasonal mean PI and VWS do not change much in the region where supertyphoons develop (see Figs. 8d,e and 9a,b), we investigate here whether there is any change in the distribution of these quantities along the actual TC tracks. Figures 11a and 11b show frequency distributions of the storm-ambient PI (Kossin and Camargo 2009) and VWS for the AMIP and TS supertyphoon composites, defined as their maximum values within a $3^{\circ}$ radius from the storm center, and sampled during the intensification period from the tropical storm strength to the lifetime maximum intensity. Even though the difference in the peaks of the PI distributions is not large compared to the spread, future supertyphoons tend to encounter significantly higher PIs during their intensification period compared to the present-day systems (Fig. 11a). They also tend to experience somewhat higher VWS, although the shift in the
VWS distribution is smaller compared to the PI (Fig. 11b). To reduce the effects that the storms themselves have on the ambient PI and VWS values, we spectrally filter these fields to remove the storm spatial scale $(\sim 1000 \mathrm{~km})$. The adjusted ambient PI and VWS are then defined as the regional averages of the filtered fields within $5^{\circ}$ from the storm center. This alternative approach does not change the results for PI, where a distinct, albeit smaller, shift toward higher values in a future climate is still present. However, the shift in the ambient VWS distribution practically disappears (not shown). These results suggest that the increase in the peak intensity of the future supertyphoons likely results from a tendency of the local storm-ambient environment to exhibit higher PI values in a future climate.

In addition to the PI and VWS, a number of other large-scale environmental factors have been suggested to alter the TC development rate. For example, $\mathrm{Li}$ et al. (2012) obtained faster TC development under lower planetary vorticity conditions based on an idealized modeling study. In the observational analysis of Wang and Zhou (2008), they found that a southward shift of TC formation in the NWPac favors rapid intensification. In addition, rapidly intensifying typhoons tend to have higher midlevel relative humidity and lowertropospheric conditional instability in their vicinity compared to other classes of storms (Hendricks et al. 2010). Storm-ambient convective available potential energy (CAPE) is also found to impact the simulated minimum central pressure (Knutson and Tuleya 1999; Shen et al. 2000), although in the modeling study of Persing and Montgomery (2005) the connection between CAPE and the maximum possible intensity, as measured by the quasi-steady maximum surface wind speed, has not been identified. Wang and Zhou (2008) have also suggested that higher low-level background relative vorticity is conducive to rapid intensification, although this is not supported by the analysis of Hendricks et al. (2010). In our simulation, the faster-developing future supertyphoons also tend to occur farther to the south during their intensification period (Fig. 11c) and propagate in an environment that is moister (Fig. 11d) and conditionally more unstable (Fig. 11e). If the spectrally truncated $500-\mathrm{hPa}$ relative humidity is averaged over $10^{\circ}$ from the storm center instead of $5^{\circ}$, thus incorporating more of the synoptic-scale environment, the shift in the distributions becomes larger with a noticeable difference between the peaks (not shown). In contrast, there is practically no systematic difference in the storm-ambient $850-\mathrm{hPa}$ relative vorticity (Fig. 11f), which is in general agreement with the results of Hendricks et al. (2010). 

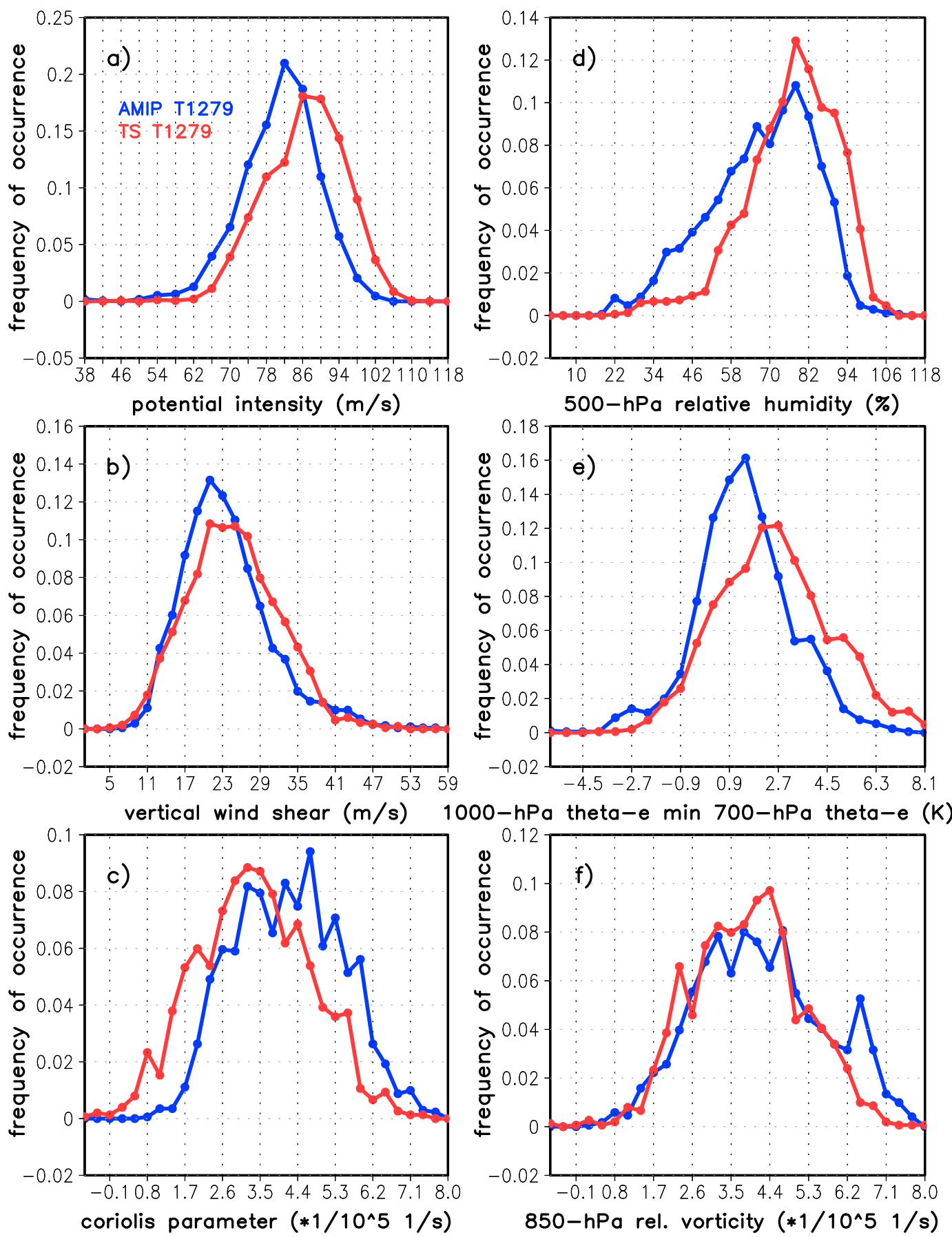

FIG. 11. Frequency distributions of the storm-ambient (a) potential intensity $\left(\mathrm{m} \mathrm{s}^{-1}\right)$, (b) vertical wind shear $\left(\mathrm{m} \mathrm{s}^{-1}\right)$, (c) Coriolis parameter $\left(10^{-5} \mathrm{~s}^{-1}\right)$, (d) 500-hPa relative humidity (\%), (e) equivalent potential temperature difference (K) between 1000 and $700 \mathrm{hPa}$, and (f) $850-\mathrm{hPa}$ relative vorticity $\left(10^{-5} \mathrm{~s}^{-1}\right)$ for the AMIP T1279 (blue) and TS T1279 (red) composites of about 50 most intense supertyphoons during their intensification phase (see more detail in the text). Quantities shown are defined as maximum values within a $3^{\circ}$ radius from the storm center in (a) and (b), and as $5^{\circ}$ averages within the storm center after the fields are truncated at T21 in (d)-(f). 
In summary, supertyphoons in a future climate tend to develop more to the south, and within an environment that possesses higher PI values and is also thermodynamically more favorable for deep convection and vortex intensification. These conditions are consistent with faster development and higher intensities characteristic of future supertyphoons. Large-scale dynamical conditions in the vicinity of these storms, like VWS and lowlevel relative vorticity, virtually remain unchanged.

\section{b. Changes in the vertical structure of the most intense supertyphoons}

To substantiate the results of the previous section, we compare structural characteristics of the supertyphoons described above. Regional sampling of the fields associated with a propagating storm is performed in a radial coordinate system centered on the storm center [details in Bengtsson et al. (2007b)]. Prior to compositing, the radial grid is oriented with the direction of storm propagation to reduce the influence of storm direction on the composite structure. Further details are similar to Manganello et al. (2012), except for the following: 1) the storm center at each level is defined as a maximum in the full-resolution (T1279) vorticity field and 2) geophysical fields are also sampled at full resolution. Results presented below primarily show radius-height plots of azimuthal mean fields, as the main focus here is on changes in the vertical structure. Comparison of the composites is made at the time when storms in each sample reach maximum intensity.

\section{1) DYNAMICAL STRUCTURE}

The primary circulation of the AMIP composite (Fig. 12a) shows cyclonic flow throughout the troposphere with a well-defined inner core, azimuthal mean tangential wind maximum of approximately $58 \mathrm{~m} \mathrm{~s}^{-1}$ at $850 \mathrm{hPa}$ and radius of maximum winds (RMW) at around $0.5^{\circ}$. The secondary circulation displays a layer of radial inflow about $2 \mathrm{~km}$ deep in the lower troposphere and an outflow in the upper troposphere (Fig. 12b). The maximum inflow (outflow) is approximately $-15 \mathrm{~m} \mathrm{~s}^{-1}\left(15 \mathrm{~m} \mathrm{~s}^{-1}\right)$. These results are in overall agreement with our prior analysis using the same model [see Figs. 7f,j in Manganello et al. (2012)]. The rising branch of the secondary circulation (Fig. 12c) shows an indication of a bimodal distribution with one maximum at $700 \mathrm{hPa}$ below the freezing level, which is at about $400 \mathrm{hPa}$ in the inner core, and another at $200 \mathrm{hPa}$. This feature is found in a number of observational and modeling studies [see Fierro et al. (2009) and the references therein], suggesting that the lower maximum could be attributed to dynamic forcing (frictional convergence) while the upper one could be due to buoyancy
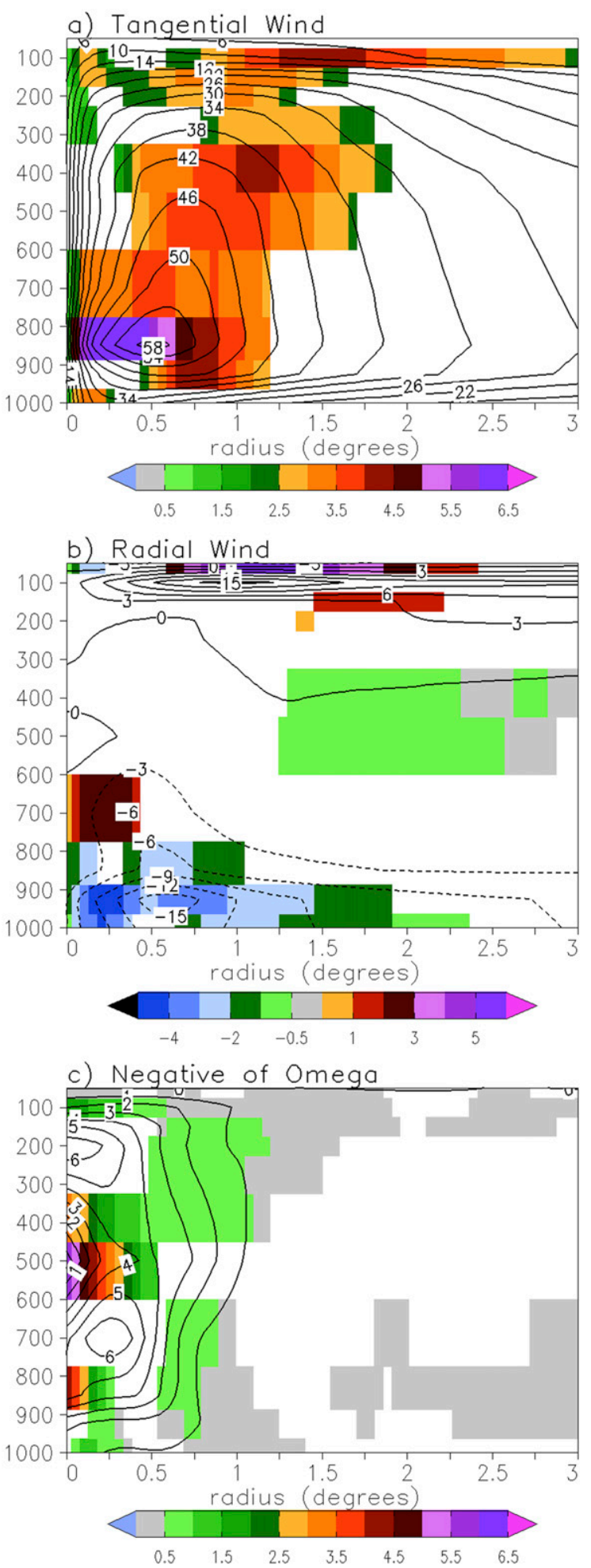

FIG. 12. Azimuthally averaged present-day (AMIP) distributions (contour) and projected (TS - AMIP) changes (shading; only differences statistically significant at the $95 \%$ confidence level are shown) of the (a) tangential wind $\left(\mathrm{ms}^{-1}\right)$, (b) radial wind $\left(\mathrm{m} \mathrm{s}^{-1}\right)$, and (c) negative of $\omega\left(\mathrm{Pa} \mathrm{s}^{-1}\right)$, based on the composites of about 50 most intense supertyphoons in the AMIP and TS at T1279 (see Table 8) at the time of their peak intensity. Contour interval is $4 \mathrm{~m} \mathrm{~s}^{-1}$ in (a), $3 \mathrm{~m} \mathrm{~s}^{-1}$ in (b), and $1 \mathrm{~Pa} \mathrm{~s}^{-1}$ in (c) and negative contours are dashed. 
effects. While many of the structural features of the TC composite described above are quite realistic, Fig. 12 clearly shows that IFS at T1279 does not fully resolve a TC eye and related processes. Although some TCs in the composite exhibit subsidence in the vicinity of the storm's center (not shown), overall the region of subsidence is not clearly defined, and updrafts are too confined to the center and do not exhibit an outward slope with height. These deficiencies are likely a result of the resolution still being too coarse to fully resolve inner core processes, although the choice of parameterizations such as for horizontal diffusion could matter as well.

In response to climate change, the inflow in the boundary layer is substantially amplified, particularly inside the RMW (Fig. 12b). There is also an anomalous outflow above the shallow inflow. The model is also able to simulate a weak anomalous inflow in the mid to upper troposphere, which is considered to be important for intensification and the inner-core warming [see Gopalakrishnan et al. (2011) and the references therein]. The upper-tropospheric outflow is also enhanced and appears to extend to higher altitudes, although because of a very coarse vertical output resolution at these levels it is hard to discern these changes. In turn, the tangential winds increase in the inner core throughout the troposphere (Fig. 12a), in correspondence with an overall intensity change (Fig. 10). The largest increase occurs at the level of maximum winds (at the top of the boundary layer) inside the eyewall, which is consistent with stronger inflow penetrating closer to the storm center. This results in a slight reduction of the RMW and the overall size of the composited TC, based on the radius of the $17 \mathrm{~m} \mathrm{~s}^{-1}$ isotach (not shown). It is interesting that these results are in overall agreement with the recent findings of Kanada et al. (2013), who used a nonhydrostatic regional model at 2-km horizontal resolution to downscale a small number of very intense typhoons generated in climate change experiments with a global AGCM. They also report that the tangential wind distribution becomes taller and narrower in the future climate, RMW decreases, and more intense inflows penetrate closer to the storm center, although in their study these changes are more evident.

Stronger inflow and outflow in the future supertyphoons by continuity must result in a larger upward mass flux in the eyewall. Indeed, the updrafts are stronger above the boundary layer, consistent with the inflow changes (Fig. 12c), and in the midtroposphere. The similarity with the results of Kanada et al. (2013) is more limited here, partly due to the difficulties with the simulation of an eye as previously stated, although they also find that the area of intense updrafts extends closer to the storm center and to lower levels, with the strongest updrafts moving to higher altitudes.
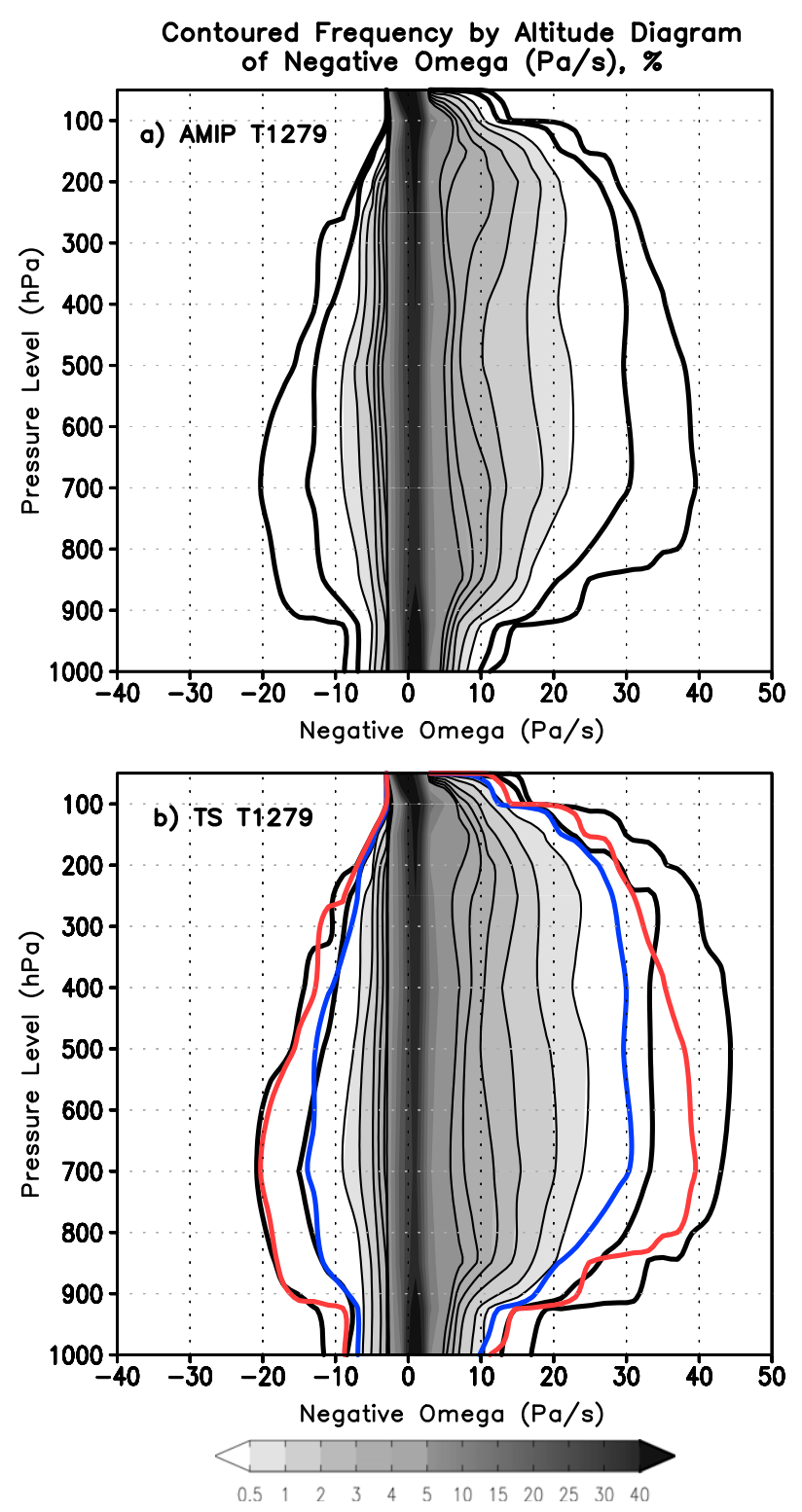

FIG. 13. Contoured frequency by altitude diagrams (CFADs) of the negative $\omega\left(\mathrm{Pa} \mathrm{s}^{-1}\right)$ based on the composites of about 50 most intense supertyphoons in the (a) AMIP T1279 and (b) TS T1279 (see Table 8), at the time of their peak intensity. The thin black contours are $0.5 \%, 1 \%, 2 \%, 3 \%, 4 \%$, and $5 \%$ of vertical motions, and the thick black contours are $0.1 \%$ and $0.01 \%$. In (b), the $0.1 \%$ and $0.01 \%$ contours are shown in blue and red, respectively, from the AMIP simulation in (a). Bin size is $2 \mathrm{Pas}^{-1}$ and CFADs are taken from grid points within $1.5^{\circ}$ from the TC center.

To assess the impact of climate change on the full distribution of vertical velocity including the extremes, such as the maximum updrafts and downdrafts, we compare contoured frequency by altitude diagrams (CFADs; e.g., Yuter and Houze 1995) of the negative of $\omega$, constructed for the AMIP and TS supertyphoon composites (Fig. 13). In the AMIP profile (Fig. 13a), the 
range of vertical motions is almost uniform with height, including the very strong updrafts ( $0.1 \%$ of occurrence), which have been linked to the coarseness of the model grid (e.g., Gentry and Lackmann 2010). Only the extremely strong updrafts and downdrafts $(0.01 \%$ of occurrence) show variation with height, where the largest values are attained at about the $700-\mathrm{hPa}$ level. The range of vertical motions is somewhat underestimated as well: updrafts less than about $15 \mathrm{~Pa} \mathrm{~s}^{-1}$ (roughly equivalent to the vertical velocity in height coordinates equal to $2 \mathrm{~m} \mathrm{~s}^{-1}$ ) represent $98 \%-99 \%$ of upward vertical motions in the eyewall compared to $70 \%-95 \%$ in the observational and high-resolution modeling studies [see, e.g., Fierro et al. (2009) and Gentry and Lackmann (2010), and the references therein]. The most extreme updrafts reach only $41 \mathrm{~Pa} \mathrm{~s}^{-1}$ (or about $5 \mathrm{~m} \mathrm{~s}^{-1}$ ) as opposed to 10$12 \mathrm{~m} \mathrm{~s}^{-1}$ in observations (see references above). In response to climate change, the frequency of the intense updrafts increases throughout the troposphere (Fig. 13b). The very strong updrafts $(0.1 \%$ of occurrence) increase in magnitude rather uniformly with height. The extremely strong updrafts $(0.01 \%$ of occurrence $)$ become more intense mainly at the surface, above the boundary layer, and in the middle troposphere, which is similar to the azimuthally mean changes in the vertical velocity shown in Fig. 12c. As a result, the maximum updraft speeds increase in the future climate with the largest values shifting to higher altitudes (between 600 and $400 \mathrm{hPa}$ ). There is no clear change in the distribution of downdrafts, except for a slight increase in the downdraft speeds at the surface.

\section{2) THERMODYNAMIC STRUCTURE}

Coherent changes in the dynamical structure of supertyphoons in a future climate, as described above, are consistent with their overall higher intensities derived from the surface-based quantities. The analysis is now extended to thermodynamic fields to further our understanding of the TC intensity changes. Consistent with the well-developed secondary circulation, the AMIP composite has a distinct warm core throughout the troposphere with a maximum anomaly of approximately $18 \mathrm{~K}$ at about $200 \mathrm{hPa}$ (Figs. 14a,d). Specific humidity is elevated in the inner core (Figs. 14b,e) in agreement with strong updrafts there that extend to the boundary layer. As a result, equivalent potential temperature $\left(\theta_{e}\right)$ attains the highest values in this region and is practically conserved with height in the eyewall (Figs. 14c,f). The latter is characteristic of undilute moistneutral ascent (e.g., Hawkins and Imbembo 1976).

In a warmer climate, the largest increase in $\theta_{e}$ occurs in the boundary/inflow layer, particularly at the surface, and the inner core (Fig. 14c). The change in the boundary layer extends as far as $5^{\circ}$ from the composite storm center (not shown) and results from the increase in temperature (Fig. 14a) and particularly specific humidity (Fig. 14b), as relative humidity remains almost the same (not shown). Figure $14 \mathrm{c}$ also suggests that a comparable gain in the inner-core $\theta_{e}$ throughout the troposphere results from an upward transport of higher entropy boundary layer air by means of the forced eyewall ascent (leading to the largest enhancement at midlevels; Figs. 14e,f) and a stronger upper-tropospheric latent heat release, mostly above $200 \mathrm{hPa}$ (Fig. 14d). The latter leads to the deepening of the warm core, which is consistent with the upward shift of the outflow layer (Fig. 12b), azimuthal mean upward motion (Fig. 12c), and the frequency of extremely strong updrafts (Fig. 13b).

\section{Discussion and conclusions}

This study investigates future changes in the NWPac TC activity projected by the multidecadal simulations with the 16-km ECMWF IFS under the IPCC A1B emissions scenario, thereby extending the horizontal resolution of such global model simulations to below $20 \mathrm{~km}$. We also compare the results to analogous simulations with the $125-\mathrm{km}$ IFS, to further identify the benefits of high versus low resolution in simulating TC climatology, variability, and change in a future climate. Considering large interannual and interdecadal variations in the NWPac TC activity, it remains uncertain whether there has been any detectable anthropogenic influence on the TC activity in this basin (Lee et al. 2012). The focus of the present study is largely on the projected changes in the typhoon activity at the end of the twenty-first century compared to the end of the twentieth century.

Both resolutions are found to reproduce many aspects of the present-day typhoon activity quite well. Consistent with other studies, the 16-km IFS clearly stands out because of its ability to represent systems at the high end of the intensity scale and a significantly better simulation of genesis locations. We also find that it shows a markedly better skill in reproducing changes in the TC intensity distribution on the interannual time scales and in response to ENSO, as well as shifts in genesis related to ENSO. Nevertheless, the magnitude of the changes in the intensity distribution, both forced and a result of the model's natural variability, is quite low compared to that observed and needs to be kept in mind when evaluating future changes. It is notable that even the downscaling method of Emanuel that utilizes a simplified very highresolution coupled model that can generate a great number of cases cannot reproduce ENSO-related 
a) Temperature

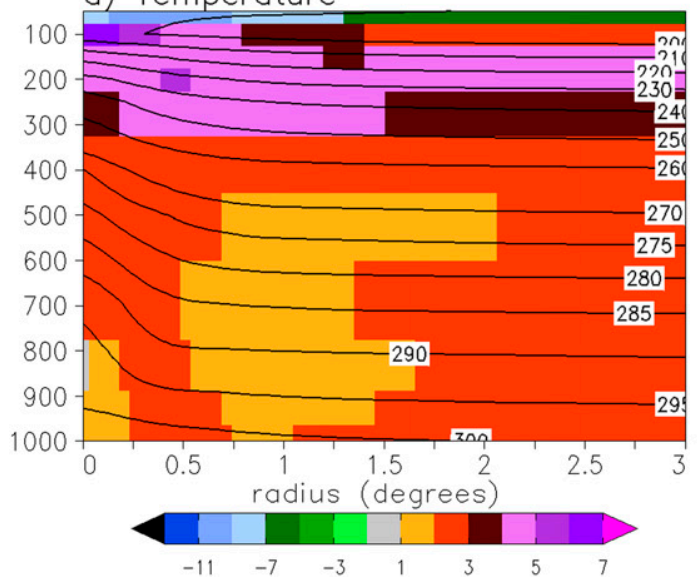

b) Specific Humidity

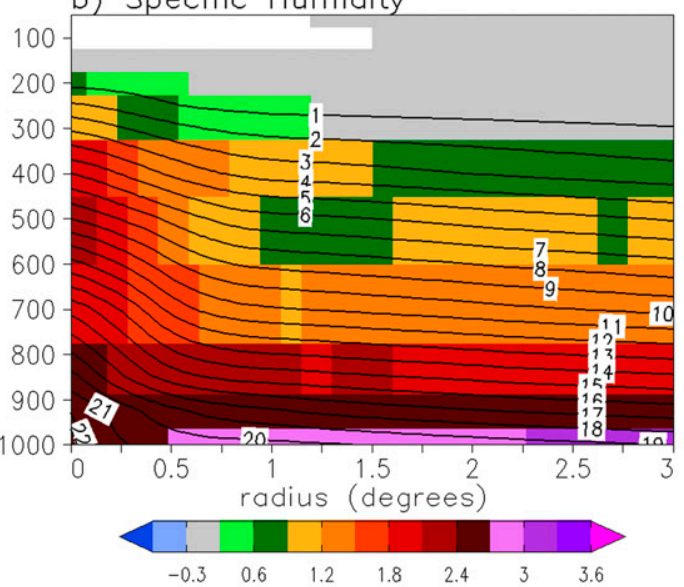

c) Equivalent Potential Temp.

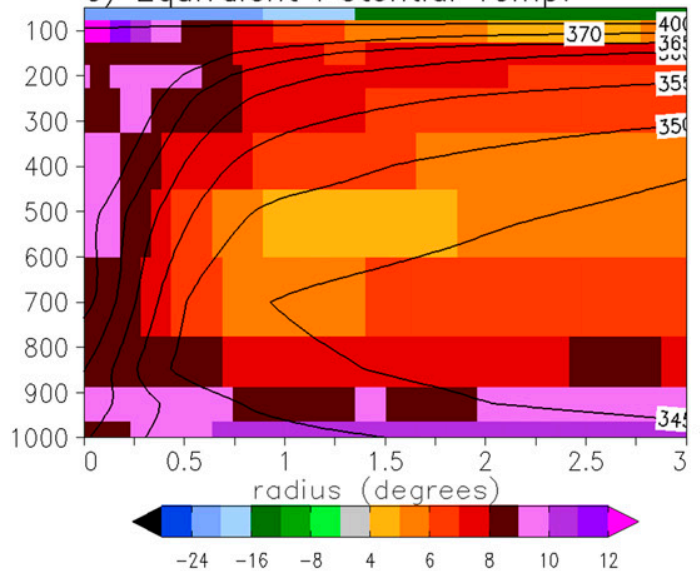

d) Temperature

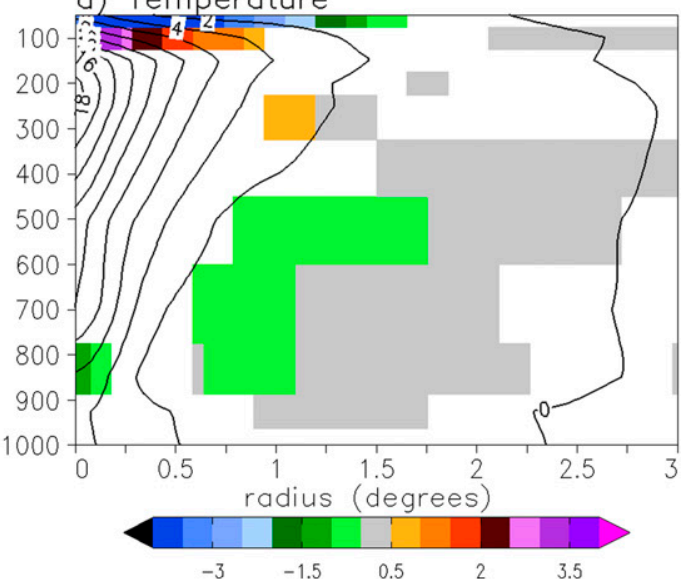

e) Specific Humidity

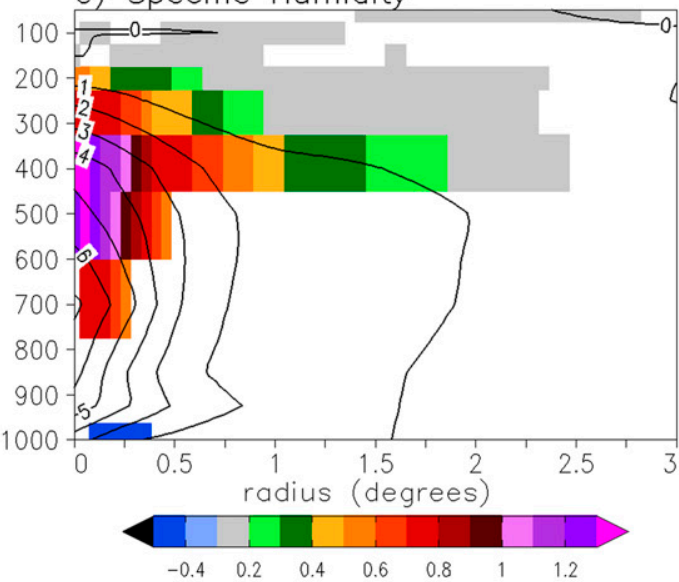

f) Equivalent Potential Temp.

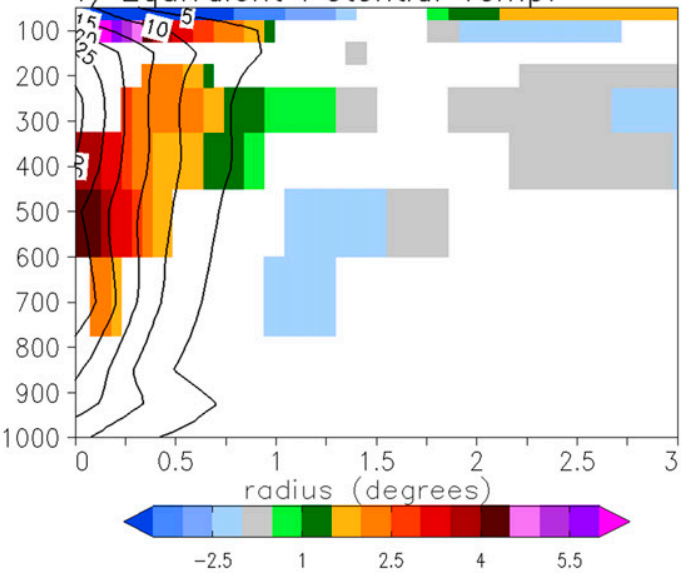

FIG. 14. Azimuthally averaged present-day (AMIP) distributions (contour) and projected (TS - AMIP) changes (shading; only differences statistically significant at the $95 \%$ confidence level are shown) of the (a) temperature (K), (b) specific humidity $\left(\mathrm{g} \mathrm{kg}^{-1}\right)$, and (c) equivalent potential temperature (K), based on the composites of about 50 most intense supertyphoons in the AMIP and TS T1279 (see Table 8) at the time of their peak intensity. (d)-(f) As in (a)-(c), except anomalies relative to the storm-ambient conditions (defined as azimuthal and radial means within $5^{\circ}$ from the composite TC center) are shown. Contour interval is $10^{\circ} \mathrm{K}$ in (a), $1 \mathrm{~g} \mathrm{~kg}^{-1}$ in (b) and (e), $5 \mathrm{~K}$ in (c) and (f), and $2 \mathrm{~K}$ in $(\mathrm{d})$. 
changes in the intensity distribution as large as observed (Emanuel et al. 2008), which indicates that it may not be just a resolution issue. This further emphasizes the need for global model improvements to increase the accuracy of climate change projections of the TC intensity change and related metrics, in addition to providing reliable estimates of the changes in the forcing fields (global and regional SST changes, greenhouse gases, aerosols, etc.) that are used to drive the AGCMs.

In contrast to a number of recent global modeling studies (Li et al. 2010; Murakami et al. 2011; Murakami et al. 2012a,b; Zhao and Held 2012; see also a review by Ying et al. 2012), both versions of the IFS project a small and insignificant change in the future NWPac TC frequency as a result of a distinct shift in the genesis locations. It appears that these differences are largely due to a different nature of the simulated climate change in the region. It amounts to an increase in the deep convective activity in the central equatorial Pacific with the largest response west of the date line, and concomitant strengthening of the monsoon trough in the southeastern part of the domain including southward penetration of the NWPac subtropical high. Our results agree with the IPCC AR4 multimodel ensemble-mean response in that the largest increase in precipitation and convective mass flux takes place in the central equatorial Pacific (Vecchi and Soden 2007b). The main differences include a weaker reduction of convective mass flux over the Maritime Continent and no change in precipitation and deep convective activity over the western north Indian Ocean.

Uncertainties in the future projections of the TC activity could stem from the uncertainties in the future forcing fields generated by coupled climate models, and uncertainties in the response to these fields by atmospheric models integrated in the time-slice mode. The role of the former uncertainties could be quite significant (e.g., Ying et al. 2012), which is not addressed in the present study mostly because of a large computational cost associated with integrating an AGCM at such high horizontal resolution as $16 \mathrm{~km}$. The time-slice approach by design neglects future changes in the interannual variability of SST, including ENSO. Since models have large biases in the simulation of relevant aspects of the present climate (e.g., Schneider et al. 2009), and there is no current consensus on the future change of ENSO (e.g., Guilyardi 2006), a suite of multimodel ensemble integrations would be required to address this additional uncertainty. Although the results of our study could be viewed as one possible realization of the future climate change and the associated impact on the typhoon activity, a number of issues like the influence of model biases and climate sensitivity need to be clarified.
The high-resolution version of the IFS clearly shows that in a future climate scenario, such as obtained from the CCSM3.0 A1B experiment, the frequency of typhoons and of very intense (category 3-5) typhoons increases significantly. It is accompanied by a corresponding reduction in the frequency of weaker storms, hence contributing to the growing consensus on this subject. This results in a significant increase $(12 \%)$ in the mean peak TC intensity and largely determines the $51 \%$ increase in the PDI. These changes are considerable to the extent that they are comparable to the model's natural variability in the current climate. Analysis of the intensity life cycle of the large supertyphoon composites has indicated that along with the mean peak intensities the development rate of this category of storms also increases in the future climate. TC intensification and intensity are controlled by a number of thermodynamic and dynamic processes that could be internal to the system or result from a TC interaction with the largescale environment [see, e.g., Zeng et al. (2007) and references therein]. By examining only the environmental influence in this study, we have found that future supertyphoons tend to develop within an environment that is thermodynamically more favorable for faster development and higher intensities, in addition to occurring more to the south, which could also enhance their intensification rate. In contrast, the distributions of the storm-ambient dynamical forcings, such as VWS and low-level relative vorticity, remain virtually unchanged in the future climate. Our study further extends the findings of Wing et al. (2007) and Kossin and Camargo (2009), namely that in order to make accurate projections of the future TC intensity change, identifying changes in the full distributions of the local stormambient large-scale conditions would be necessary, as comparison of the regional and seasonal means is of limited value. This would require placing higher confidence in the future projections of genesis locations and track changes. Finally, we would like to add that in a more realistic experimental setting, where interaction with the underlying ocean is included, the rate of TC intensification in the future would likely be reduced. This is so because of a negative feedback of the TCinduced upper ocean mixing (stirring of warm surface waters with colder water in the thermocline) on TC intensity (e.g., Schade and Emanuel 1999), which is more pronounced for strong TCs. On the other hand, Knutson et al. (2001) have shown that percentage increase in the TC intensity is not affected by the ocean coupling. As the thermocline depth is projected to shoal in the western equatorial Pacific and deepen to the north (Vecchi and Soden 2007b), it is not exactly clear what would be the net effect of the above feedback. Ultimately, simulations 
with high-resolution coupled atmosphere-wave-ocean GCMs would be able to answer these questions.

The increase in the intensity of the future supertyphoons is reflected in their structural changes where the primary and secondary circulations show systemscale amplification with signs of contraction. A more vigorous eyewall ascent, which transports higher entropy air available at the surface in a warmer climate to upper levels, results in a stronger diabatic heating aloft and a strengthening of the warm core. A deeper warm core is accompanied by an upward shift in the outflow layer and the frequency of the most intense updrafts. Specifically, the frequency of intense updrafts $(0.1 \%$ of occurrence) is higher throughout the troposphere with no changes in downdrafts, and the extremely strong updrafts $(0.01 \%$ of occurrence) are more intense, particularly in the mid to upper troposphere. The latter result is somewhat different from the regional simulations of Hill and Lackmann (2011) at 2-km resolution where the change in maximum updraft speeds is not observed, and stronger upward motion is found only above the level of maximum updrafts.

Finally, we emphasize that the differences between the high- and low-resolution versions of the IFS in simulating future typhoon activity are quite staggering. In addition to the expected effect of model resolution on the TC intensity distribution, the 125-km IFS has a difficulty in simulating systems of tropical origin that intensify within the tropical environment, which is also pertinent to other coarse-resolution models (Bengtsson et al. 2006, 2007a; Strachan et al. 2013), thus severely limiting the value of these climate change projections. This further calls for thorough evaluation of models' ability to simulate present-day TC activity-particularly so for coarse-resolution AGCMs or coupled GCMsand caution in interpreting projections from such lowresolution models.

Acknowledgments. The results described herein were obtained in the 2009-10 Athena Project, a computationally intensive project that was carried out using the Athena supercomputer at the University of Tennessee's National Institute for Computational Sciences (NICS), under the auspices of the National Science Foundation (NSF). Support provided by the NICS, the NSF (Grants 0830068 and 0957884), NOAA (Grant NA09OAR4310058), and NASA (Grant NNX09AN50G) is gratefully acknowledged. We also acknowledge the support of the European Centre for Medium-Range Weather Forecasts (ECMWF), which provided the IFS code, boundary and initial conditions datasets, and run scripts. We are thankful to Dr. David Nolan (University of Miami) for helpful discussions, Dr. David Straus (COLA) for the help with spectral processing, Dr. Xiasong Yang (COLA) for assistance with computing, and three anonymous reviewers for their constructive comments on our manuscript. The following individuals contributed to the project: P. Dirmeyer, B. Doty, and T. Wakefield (COLA); P. Bechtold, M. Fuentes, M. Hamrud, M. Miller, and T. Palmer (ECMWF); M. Satoh (University of Tokyo, Japan); H. Tomita (RIKEN Advanced Institute for Computational Sciences-AICS, Japan); C. Kodama and Y. Yamada (Japan Agency for Marine-Earth Science and Technology-JAMSTEC, Japan); P. Andrews, T. Baer, M. Ezell, C. Halloy, D. John, B. Loftis, and K. Wong (NICS, United States); and P. Johnsen and P. Nyberg (Cray, Inc.).

\section{REFERENCES}

Bell, R., J. Strachan, P. L. Vidale, K. Hodges, and M. Roberts, 2013: Response of tropical cyclones to idealized climate change experiments in a global high-resolution coupled general circulation model. J. Climate, 26, 7966-7980, doi:10.1175/ JCLI-D-12-00749.1.

Bender, M. A., T. R. Knutson, R. E. Tuleya, J. J. Sirutis, G. A. Vecchi, S. T. Garner, and I. M. Held, 2010: Modeled impact of anthropogenic warming on the frequency of intense Atlantic hurricanes. Nature, 327, 454-458, doi:10.1126/science.1180568.

Bengtsson, L., M. Botzet, and M. Esch, 1996: Will greenhouse gasinduced warming over the next 50 years lead to higher frequency and greater intensity of hurricanes? Tellus, $\mathbf{4 8 A}$, 5773, doi:10.1034/j.1600-0870.1996.00004.x.

—, K. I. Hodges, and E. Roeckner, 2006: Storm tracks and climate change. J. Climate, 19, 3518-3543, doi:10.1175/ JCLI3815.1.

,$- \ldots$, and M. Esch, 2007a: Tropical cyclones in a T159 resolution global climate model: Comparison with observations and re-analyses. Tellus, 59A, 396-416, doi:10.1111/ j.1600-0870.2007.00236.x.

,$--\ldots$, N. Keenlyside, L. Kornblueh, J.-J. Luo, and T. Yamagata, 2007b: How may tropical cyclones change in a warmer climate? Tellus, 59A, 539-561, doi:10.1111/ j.1600-0870.2007.00251.x.

Camargo, S. J., and A. H. Sobel, 2005: Western North Pacific tropical cyclone intensity and ENSO. J. Climate, 18, 29963006, doi:10.1175/JCLI3457.1.

_ K. A. Emanuel, and A. H. Sobel, 2007: Use of a genesis potential index to diagnose ENSO effects on tropical cyclone genesis. J. Climate, 20, 4819-4834, doi:10.1175/JCLI4282.1.

Chan, J. C. L., and K. S. Liu, 2004: Global warming and western North Pacific typhoon activity from an observational perspective. J. Climate, 17, 4590-4602, doi:10.1175/3240.1.

Chia, H. H., and C. F. Ropelewski, 2002: The interannual variability in the genesis location of tropical cyclones in the northwest Pacific. J. Climate, 15, 2934-2944, doi:10.1175/ 1520-0442(2002)015<2934:TIVITG > 2.0.CO;2.

Emanuel, K. A., 2000: A statistical analysis of tropical cyclone intensity. Mon. Wea. Rev., 128, 1139-1152, doi:10.1175/ 1520-0493(2000)128<1139:ASAOTC>2.0.CO;2.

- 2005: Increasing destructiveness of tropical cyclones over the past 30 years. Nature, 436, 686-688, doi:10.1038/ nature 03906 . 
- 2007: Environmental factors affecting tropical cyclone power dissipation. J. Climate, 20, 5497-5509, doi:10.1175/ 2007JCLI1571.1.

—, R. Sundararajan, and J. Williams, 2008: Hurricanes and global warming: Results from downscaling IPCC AR4 simulations. Bull. Amer. Meteor. Soc., 89, 347-367, doi:10.1175/ BAMS-89-3-347.

Fierro, A. O., R. F. Rogers, F. D. Marks, and D. S. Nolan, 2009: The impact of horizontal grid spacing on the microphysical and kinematic structures of strong tropical cyclones simulated with the WRF-ARW model. Mon. Wea. Rev., 137, 3717-3743, doi:10.1175/2009MWR2946.1.

Gates, W. L., 1992: AMIP: The Atmospheric Model Intercomparison Project. Bull. Amer. Meteor. Soc., 73, 1962-1970, doi:10.1175/1520-0477(1992)073<1962:ATAMIP>2.0.CO;2.

Gentry, M. S., and G. M. Lackmann, 2010: Sensitivity of simulated tropical cyclone structure and intensity to horizontal resolution. Mon. Wea. Rev., 138, 688-704, doi:10.1175/2009MWR2976.1.

Gopalakrishnan, S. G., F. Marks, X. Zhang, J.-W. Bao, K.-S. Yeh, and R. Atlas, 2011: The experimental HWRF system: A study on the influence of horizontal resolution on the structure and intensity changes in tropical cyclones using an idealized framework. Mon. Wea. Rev., 139, 1762-1784, doi:10.1175/ 2010MWR3535.1.

Guilyardi, E., 2006: El Niño-mean state-seasonal cycle interactions in a multi-model ensemble. Climate Dyn., 26, 329348, doi:10.1007/s00382-005-0084-6.

Harper, B. A., J. D. Kepert, and J. D. Ginger, 2009: Guidelines for converting between various wind averaging periods in tropical cyclone conditions. World Meteorological Organization, TCMVI/Doc. 2.3, 62 pp. [Available online at https://www.wmo.int/ pages/prog/www/tcp/documents/Doc2.3_WindAveraging.pdf.]

Hawkins, H. F., and S. M. Imbembo, 1976: The structure of a small, intense hurricane-Inez 1966. Mon. Wea. Rev., 104, 418-442, doi:10.1175/1520-0493(1976)104<0418:TSOASI >2.0.CO;2.

Hendricks, E. A., M. S. Peng, B. Fu, and T. Li, 2010: Quantifying environmental control on tropical cyclone intensity change. Mon. Wea. Rev., 138, 3243-3271, doi:10.1175/2010MWR3185.1.

Hill, K. A., and G. M. Lackmann, 2011: The impact of future climate change on TC intensity and structure: A downscaling approach. J. Climate, 24, 4644-4661, doi:10.1175/ 2011JCLI3761.1.

Hodges, K. I., 1994: A general method for tracking analysis and its application to meteorological data. Mon. Wea. Rev., 122, 2573-2586, doi:10.1175/1520-0493(1994)122<2573: AGMFTA $>2.0 . \mathrm{CO} ; 2$.

- 1995: Feature tracking on the unit sphere. Mon. Wea. Rev., 123, 3458-3465, doi:10.1175/1520-0493(1995)123<3458: FTOTUS $>2.0 . \mathrm{CO} ; 2$.

1999: Adaptive constraints for feature tracking. Mon. Wea Rev., 127, 1362-1373, doi:10.1175/1520-0493(1999)127<1362 ACFFT $>2.0 . \mathrm{CO} ; 2$.

_ 2008: Confidence intervals and significance tests for spherical data derived form feature tracking. Mon. Wea. Rev., 136, 1758-1777, doi:10.1175/2007MWR2299.1.

Jung, T., and Coauthors, 2012: High-resolution global climate simulations with the ECMWF model in Project Athena: Experimental design, model climate, and seasonal forecast skill J. Climate, 25, 3155-3172, doi:10.1175/JCLI-D-11-00265.1.

Kanada, S., A. Wada, and M. Sugi, 2013: Future changes in structures of extremely intense tropical cyclones using a 2-km mesh nonhydrostatic model. J. Climate, 26, 9986-10005, doi:10.1175/JCLI-D-12-00477.1.
Kinter, J. L., and Coauthors, 2013: Revolutionizing climate modelingProject Athena: A multi-institutional, international collaboration. Bull. Amer. Meteor. Soc., 94, 231-245, doi:10.1175/ BAMS-D-11-00043.1.

Klotzbach, P. J., 2006: Trends in global tropical cyclone activity over the past twenty years (1986-2005). Geophys. Res. Lett., 33, L10805, doi:10.1029/2006GL025881.

Knapp, K. R., and M. C. Kruk, 2010: Quantifying interagency differences in tropical cyclone best-track wind speed estimates. Mon. Wea. Rev., 138, 1459-1473, doi:10.1175/ 2009MWR3123.1.

,-- D. H. Levinson, H. J. Diamond, and C. J. Neumann, 2010: The International Best Track Archive for Climate Stewardship (IBTrACS). Bull. Amer. Meteor. Soc., 91, 363376, doi:10.1175/2009BAMS2755.1.

_ J. J. Knaff, C. R. Sampson, G. M. Riggio, and A. D. Schnapp, 2013: A pressure-based analysis of the historical western North Pacific tropical cyclone intensity record. Mon. Wea. Rev., 141, 2611-2631, doi:10.1175/MWR-D-12-00323.1.

Knutson, T. R., and R. E. Tuleya, 1999: Increased hurricane intensities with $\mathrm{CO}_{2}$-induced warming as simulated using the GFDL hurricane prediction system. Climate Dyn., 15, 503519, doi:10.1007/s003820050296.

$\longrightarrow$, and - 2004: Impact of $\mathrm{CO}_{2}$-induced warming on simulated hurricane intensity and precipitation: Sensitivity to the choice of climate model and convective parameterization. J. Climate, 17, 3477-3495, doi:10.1175/1520-0442(2004)017<3477: IOCWOS $>2.0 . \mathrm{CO} ; 2$.

,-- W. Shen, and I. Ginis, 2001: Impact of $\mathrm{CO}_{2}$-induced warming on hurricane intensities as simulated in a hurricane model with ocean coupling. J. Climate, 14, 2458-2468, doi:10.1175/1520-0442(2001)014<2458:IOCIWO>2.0.CO;2.

- and Coauthors, 2010: Tropical cyclones and climate change. Nat. Geosci., 3, 157-163, doi:10.1038/ngeo779.

Kossin, J. P., and S. Camargo, 2009: Hurricane track variability and secular potential intensity trends. Climatic Change, 97, 329337, doi:10.1007/s10584-009-9748-2.

_ , K. R. Knapp, D. J. Vimont, R. J. Murnane, and B. A. Harper, 2007: A globally consistent reanalysis of hurricane variability and trends. Geophys. Res. Lett., 34, L04815, doi:10.1029/ 2006 GL028836.

Landsea, C. W., 1993: A climatology of intense (or major) Atlantic hurricanes. Mon. Wea. Rev., 121, 1703-1713, doi:10.1175/ 1520-0493(1993)121<1703:ACOIMA > 2.0.CO;2.

Lee, T.-C., T. R. Knutson, H. Kamahori, and M. Ying, 2012: Impacts of climate change on tropical cyclones in the western North Pacific basin. Part I: Past observations. Trop. Cyclone Res. Rev., 1, 213-230, doi:10.6057/2012TCRR02.08.

Li, T., M. Kwon, M. Zhao, J.-S. Kug, J.-J. Luo, and W. Yu, 2010: Global warming shifts Pacific tropical cyclone location. Geophys. Res. Lett., 37, L21804, doi:10.1029/2010GL045124.

_ X. Ge, M. Peng, and W. Wang, 2012: Dependence of tropical cyclone intensification on the Coriolis parameter. Trop. Cyclone Res. Rev., 1, 242-253, doi:10.6057/2012TCRR02.04.

Manganello, J. V., and Coauthors, 2012: Tropical cyclone climatology in a $10-\mathrm{km}$ global atmospheric GCM: Toward weatherresolving climate modeling. J. Climate, 25, 3867-3893, doi:10.1175/JCLI-D-11-00346.1.

Murakami, H., and M. Sugi, 2010: Effect of model resolution on tropical cyclone climate projections. SOLA, 6, 73-76, doi:10.2151/sola.2010-019.

, B. Wang, and A. Kitoh, 2011: Future change of western North Pacific typhoons: Projections by a $20-\mathrm{km}$-mesh global 
atmospheric model. J. Climate, 24, 1154-1169, doi:10.1175/ 2010JCLI3723.1.

_ R. Mizuta, and E. Shindo, 2012a: Future changes in tropical cyclone activity projected by multi-physics and multi-SST ensemble experiments using the 60-km-mesh MRI-AGCM. Climate Dyn., 39, 2569-2584, doi:10.1007/s00382-011-1223-x.

— , and Coauthors, 2012b: Future changes in tropical cyclone activity projected by the new high-resolution MRI-AGCM. J. Climate, 25, 3237-3260, doi:10.1175/JCLI-D-11-00415.1.

Nolan, D. S., E. D. Rappin, and K. A. Emanuel, 2007: Tropical cyclogenesis sensitivity to environmental parameters in radiative-convective equilibrium. Quart. J. Roy. Meteor. Soc., 133, 2085-2107, doi:10.1002/qj.170.

Persing, J., and M. T. Montgomery, 2005: Is environmental CAPE important in the determination of maximum possible hurricane intensity? J. Atmos. Sci., 62, 542-550, doi:10.1175/JAS-3370.1.

Pielke, R. A., C. Landsea, M. Mayfield, J. Laver, and R. Pasch, 2005: Hurricanes and global warming. Bull. Amer. Meteor. Soc., 86, 1571-1575, doi:10.1175/BAMS-86-11-1571.

Powell, M. D., P. J. Vickery, and T. A. Reinhold, 2003: Reduced drag coefficient for high wind speeds in tropical cyclones. Nature, 422, 279-283, doi:10.1038/nature01481.

Schade, L. R., and K. A. Emanuel, 1999: The ocean's effect on the intensity of tropical cyclones: Results from a simple coupled atmosphere-ocean model. J. Atmos. Sci., 56, 642-651, doi:10.1175/1520-0469(1999)056<0642:TOSEOT >2.0.CO;2.

Schneider, E. K., M. J. Fennessy, and J. L. Kinter, 2009: A statisticaldynamical estimate of winter ENSO teleconnections in a future climate. J. Climate, 22, 6624-6638, doi:10.1175/ 2009JCLI3147.1.

Shen, W., R. E. Tuleya, and I. Ginis, 2000: A sensitivity study of the thermodynamic environment on GFDL model hurricane intensity: Implications for global warming. J. Climate, 13, 109-121, doi:10.1175/1520-0442(2000)013<0109:ASSOTT>2.0.CO;2.

Song, J.-J., Y. Wang, and L. Wu, 2010: Trend discrepancies among three best track data sets of western North Pacific tropical cyclones. J. Geophys. Res., 115, D12128, doi:10.1029/ 2009JD013058.

Stowasser, M., Y. Wang, and K. Hamilton, 2007: Tropical cyclone changes in the western North Pacific in a global warming scenario. J. Climate, 20, 2378-2396, doi:10.1175/JCLI4126.1.

Strachan, J., P. L. Vidale, K. Hodges, M. Roberts, and M.-E. Demory, 2013: Investigating global tropical cyclone activity with a hierarchy of AGCMs: The role of model resolution. J. Climate, 26, 133-152, doi:10.1175/JCLI-D-12-00012.1.

Trenberth, K., 2005: Uncertainty in hurricanes and global warming. Science, 308, 1753-1754, doi:10.1126/science.1112551.

Uppala, S. M., and Coauthors, 2005: The ERA-40 Re-Analysis. Quart. J. Roy. Meteor. Soc., 131, 2961-3012, doi:10.1256/ qj.04.176.

Vecchi, G. A., and B. J. Soden, 2007a: Effect of remote sea surface temperature change on tropical cyclone potential intensity. Nature, 450, 1066-1070, doi:10.1038/nature06423.

, and - 2007b: Global warming and the weakening of the tropical circulation. J. Climate, 20, 4316-4340, doi:10.1175/ JCLI4258.1.
Walsh, K., M. Fiorino, C. W. Landsea, and K. L. McInnes, 2007: Objectively determined resolution-dependent threshold criteria for the detection of tropical cyclones in climate models and reanalyses. J. Climate, 20, 2307-2314, doi:10.1175/ JCLI4074.1.

—, S. Lavender, E. Scoccimarro, and H. Murakami, 2013: Resolution dependence of tropical cyclone formation in CMIP3 and finer resolution models. Climate Dyn., 40, 585-599, doi:10.1007/s00382-012-1298-z.

Wang, B., and J. C. L. Chan, 2002: How strong ENSO events affect tropical storm activity over the western North Pacific. J. Climate, 15, 1643-1658, doi:10.1175/1520-0442(2002)015<1643: HSEEAT $>2.0 . \mathrm{CO} ; 2$.

— intensification in tropical cyclones in the western North Pacific. Meteor. Atmos. Phys., 99, 1-16, doi:10.1007/s00703-006-0238-z.

Wing, A. A., A. H. Sobel, and S. J. Camargo, 2007: Relationship between the potential and actual intensities of tropical cyclones on interannual time scales. Geophys. Res. Lett., 34, L08810, doi:10.1029/2006GL028581.

Wu, L., and B. Wang, 2004: Assessing impacts of global warming on tropical cyclone tracks. J. Climate, 17, 1686-1698, doi:10.1175/ 1520-0442(2004)017<1686:AIOGWO>2.0.CO;2.

,-- , and S. A. Brown, 2008: Implications of tropical cyclone power dissipation index. Int. J. Climatol., 28, 727-731, doi:10.1002/joc.1573.

Yamada, Y., K. Oouchi, M. Satoh, H. Tomita, and W. Yanase, 2010: Projection of changes in tropical cyclone activity and cloud height due to greenhouse warming: Global cloud-system-resolving approach. Geophys. Res. Lett., 37, L07709, doi:10.1029/2010GL042518.

Ying, M., T. R. Knutson, H. Kamahori, and T.-C. Lee, 2012: Impacts of climate change on tropical cyclones in the western North Pacific basin. Part II: Late twenty-first century projections. Trop. Cyclone Res. Rev., 1, 231-241. [Available online at http:// tcrr.typhoon.gov.cn/EN/abstract/abstract59.shtml.]

Yuter, S. E., and R. A. Houze Jr., 1995: Three-dimensional kinematic and microphysical evolution of Florida cumulonimbus. Part II: Frequency distributions of vertical velocity, reflectivity, and differential reflectivity. Mon. Wea. Rev., 123, 1941-1963, doi:10.1175/1520-0493(1995)123<1941:TDKAME>2.0.CO;2.

Zeng, Z., Y. Wang, and C.-C. Wu, 2007: Environmental dynamical control of tropical cyclone intensity-An observational study. Mon. Wea. Rev., 135, 38-59, doi:10.1175/MWR3278.1.

Zhao, M., and I. M. Held, 2010: An analysis of the effect of global warming on the intensity of Atlantic hurricanes using a GCM with statistical refinement. J. Climate, 23, 6382-6393, doi:10.1175/2010JCLI3837.1.

_, and _ 2012: TC-permitting GCM simulations of hurricane frequency response to sea surface temperature anomalies projected for the late-twenty-first century. J. Climate, 25, 2995-3009, doi:10.1175/JCLI-D-11-00313.1.

$\longrightarrow,-$ - S.-J. Lin, and G. A. Vecchi, 2009: Simulations of global hurricane climatology, interannual variability, and response to global warming using a $50-\mathrm{km}$ resolution GCM. J. Climate, 22, 6653-6678, doi:10.1175/2009JCLI3049.1. 